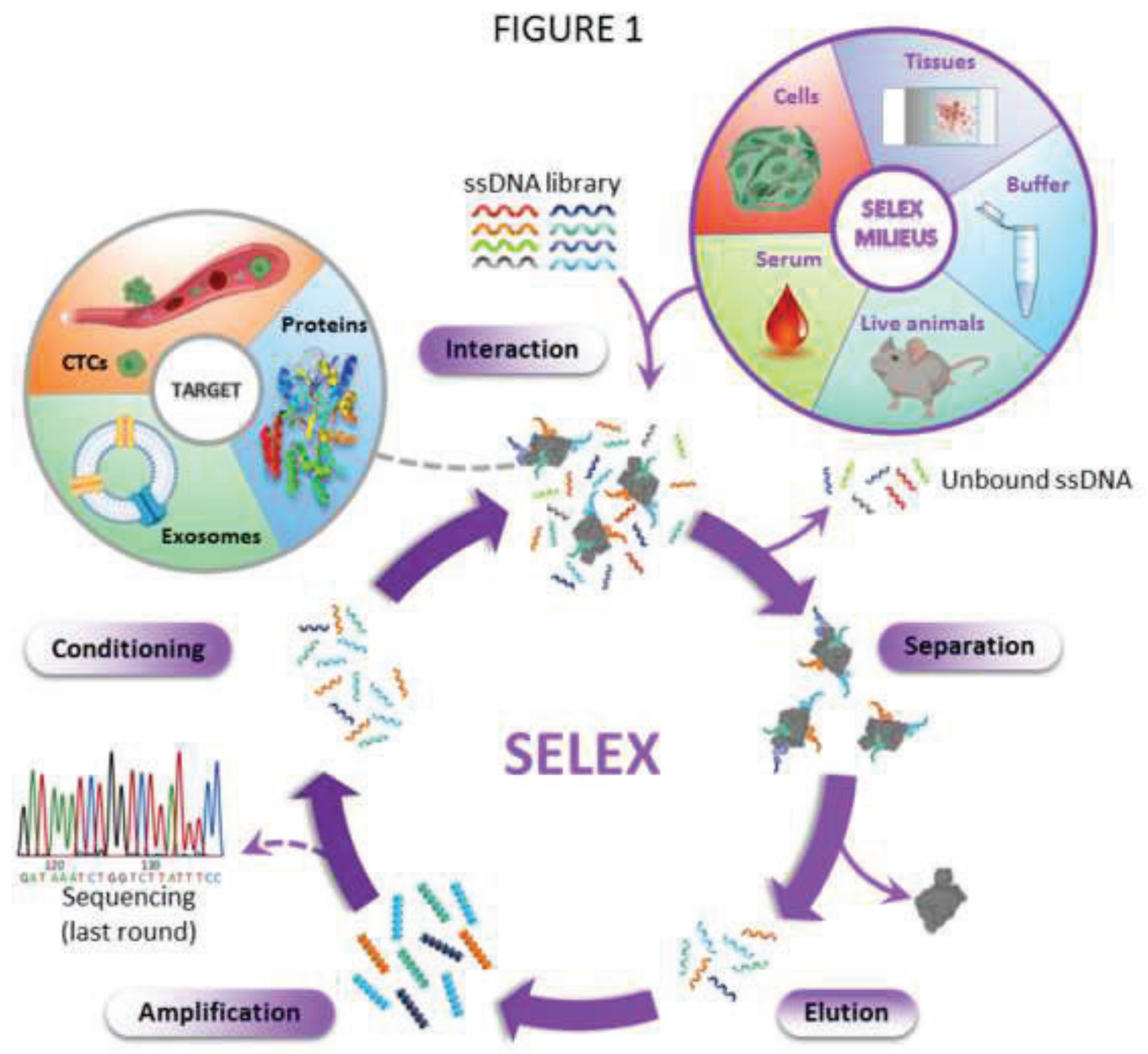




\section{Electrochemical aptasensors for cancer diagnosis in biological fluids - A review}

Ana Díaz-Fernández ${ }^{\ddagger} a, b$, Ramón Lorenzo-Gómez ${ }^{\ddagger}{ }^{a, b}$, Rebeca Miranda-Castro ${ }^{a, b}$, Noemí de-los-Santos-Álvarez ${ }^{a, b}$, María Jesús Lobo-Castañón ${ }^{a, b}$

a Dpto. Química Física y Analítica, Universidad de Oviedo, Av. Julián Clavería 8, 33006 Oviedo, Spain.

${ }^{b}$ Instituto de Investigación Sanitaria del Principado de Asturias, Avenida de Roma, 33011 Oviedo, Spain

${ }^{\ddagger}$ Both authors contribute equally

* Corresponding Author. Phone number: +34 985103490;

Email address: santosnoemi@uniovi.es

ADF: anadf@uniovi.es

RLG: lorenzoramon@uniovi.es

RMC: mirandarebeca@uniovi.es

MJLC: mjlc@uniovi.es 


\begin{abstract}
The tunability of SELEX procedure is an essential feature to supply bioaffinity receptors (aptamers) almost on demand for analytical and therapeutic purposes. This longstanding ambition is, however, not straightforward. Non-invasive cancer diagnosis, so called liquid biopsy, requires collection of body fluids with minimal or no sample pretreatment. In those raw matrices, aptamers must recognize minute amounts of biomarkers that are not unique entities but large sets of variants evolving with the disease stage. The susceptibility of aptasensors to assay conditions has driven the selection of aptamers to natural environments to ensure their optimum performance in clinical samples. We present herein a compilation of the SELEX procedures in natural millieus. By revising the electrochemical aptasensors applied to clinical samples for cancer diagnosis and tracing back to the original SELEX we analyze whether aptamers raised using these SELEX strategies are being incorporated to the diagnostic devices and how aptasensors are finding their way to a market dominated by antibody-based assays.
\end{abstract}

Keywords: aptamer; cancer; CTCs; electrochemical biosensors; exosome; SELEX, 


\section{Introduction}

Early cancer diagnosis, before imaging revealing the tumor or even clinical symptoms, is an extremely active multidisciplinary research area. Fundamental pillars are the availability of proper biomarkers that excel in clinical sensitivity and specificity as well as proper analytical methodologies that make affordable large population screenings. Unfortunately, today the only biomarker in clinical usage for this task is the prostate specific antigen (PSA), which is strongly questioned because of the increasing number of unnecessary interventions in indolent or slow-growing tumors that boost the health public budget and the anxiety and discomfort of patients [1].

All FDA-approved cancer biomarkers with prognostics, predictive and monitoring ability are detected by immunoassays, but the advent of novel receptors has triggered the development of methods with enhanced analytical features that enable improving the clinical performance of known biomarkers. That way, the selection of aptamers, since their discovery at the beginning of the 90's [2, 3], has increased notably, not only for diagnostic purposes but also as therapeutic agents or, more recently, for theranostic devices $[4,5]$.

In the first two decades of this century, the accumulated knowledge at all biochemical levels has grown extraordinarily fueled by the (analytical) methodologies that made the deciphering of human genome a sooner reality than expected. Early cancer diagnosis and recurrence must benefit from it through the genome wide analysis of mutations, and the epigenetic and post-translational modifications (PTM) of nucleic acids and proteins. Novel biomarkers within these niches are currently under investigation with the expectation of finding the gold standard biomarker for each (sub)type of this diverse disease. 
The detection of epigenetic marks or PTM on proteins is an actual analytical challenge because it involves a fraction of low abundant biomolecules. Alterations in these features can change fundamental properties of each molecule that allow direct electrochemical detection $[6,7]$, but receptor-based detection is more attractive because it is target specific. These research avenues require the development of economic, selective, renewable, and reproducible affinity receptors to unravel the function of myriads of proteoforms [8] and its clinical effectiveness to guide cancer management. Antibody reproducibility issues, openly recognized [9], are being battled [10, 11]. In fact, there are programs such as the National Cancer Institute's Antibody Characterization aimed at "having three monoclonal antibodies produced for each successfully expressed/purified recombinant antigen and one antibody per peptide (1 to 3 peptides per protein)" [12], which must be extensively characterized under public and rigorous guidelines. Aptamers are the receptors of choice when wishing to direct the recognition to specific sites on a biomarker, typically a protein. The modular concept of in-vitro selection of aptamers, schematized in Figure 1, is very suitable to include steps to eliminate sequences that bind undesired regions of the biomolecule. For details on SELEX procedure and its variants we refer the readers to specific and excellent reviews $[13,14]$. Batch to batch variation is not a concern with chemically synthesized aptamers, but similar matters regarding the poor characterization are now evident [1517] and need to be addressed.

Since the first electrochemical aptasensor [18], a variety of aptamer-based electrochemical devices to detect cancer biomarkers have appeared. Those detecting protein tumor biomarkers or, more recently CTCs, have been partially reviewed within a wider scope in terms of transduction [19-21], field of application [22, 23] or type of bioreceptors $[24,25]$. Other reviews are focused on a specific protein tumor biomarker 
[26-28], type of targets [29] or certain aspects of aptamer-based approaches such as the use of nanomaterials $[30,31]$. Our approach covers for the first time the three targets enabling liquid biopsy: protein biomarkers, CTCs, and exosomes. The latter has not been reviewed except in a brief paragraph within a very recent compilation of optical approaches [32] and a short perspective on DNA-based biosensors (genosensors and aptasensors) [33].

As long as the reported methods have not been tested in clinical samples their usefulness is not fully demonstrated. This is why, in contrast to previous reviews, our critical discussion is restricted to those. The main goal of the discussion is not the detailed enumeration of every single assay scheme, but to emphasize the suitability for its implementation in clinical settings. We trace back the aptamer sequence to the original selection process to ascertain how the selection environment determines and influences its subsequent application in body fluids. Thus, we first review the viability of using biological media or samples during the SELEX process to secure the native state of the target and ensure the successful functioning of aptamers in the in-vitro diagnostic device. This is the most often claimed pitfall with respect to antibodies [34], which are less sensitive to medium variations. The core of the revision is a critical analysis of aptamers used in electrochemical biosensors for the detection of proteins, circulating tumor cells (CTCs) and exosomes as consolidated or potential cancer biomarkers. They represent an accurate picture of the whole aptasensors world in terms of advantages and shortcomings and its potential to reach the market of medical diagnostic devices, aspects commented in the last section of this review.

\section{Aptamer selection in biological media}

An early frontier, soon surpassed, in aptamer selection was the requirement of purified single targets. Cell-SELEX first showed the suitability of complex matrices for the 
aptamer selection [35], with the benefit of preserving the native state of targets but at the expense of not knowing what the ultimate target is unless costly and timeconsuming non-straightforward post-SELEX experiments are carried out (typically in combination with mass spectrometry (MS)). At the same time, it becomes clear that recombinant proteins synthesized through genetic engineering in prokaryotic systems, easy to purify and widely used as targets, may generate aptamers that do not interact with the corresponding native counterpart. This is attributed to PTM in eukaryotes that do not take place in prokaryotic cells. In fact, native proteins are not unique molecules. On the contrary, each one is a set of proteoforms arising from DNA and RNA-levels variations, errors in transcription and translation, PTMs, exposure to toxic compounds and response to pathological states [8].

Therefore, selection of aptamers to unpurified proteins in biological media, such as serum, tissues, and post-operative samples, has attracted great interest [36] (Figure 1). An important advantage of SELEX procedures in raw materials is that they do not require deep biochemical knowledge to select the target in advance, but careful and more intensive counter-selection steps must be introduced to eliminate non-specific binding events. Besides, as a side-result, these strategies are indirect ways of biomarker screening, after proper identification.

Last year has witnessed the first attempts of using whole serum as an appealing complex target to generate aptamers for diagnostic purposes [37-39]. In all cases pooled serum from cancer diagnosed patients is used in positive rounds of selection. The extraordinary problem of cancer heterogeneity, low abundancy of specific biomarkers and discrimination from benign diseases is addressed by means of counter steps with pooled serum from healthy individuals. That is, the selection is unselectively directed toward any difference between both types of serum. DNA degradation by nucleases 
after repeated interactions in serum is not reported. Both heterogeneous and in-solution SELEX are proposed. The heterogeneous strategy is based on the immobilization of the serum components on carboxylated magnetic beads (MBs), enabling magnetic separation to discard non-specific bound DNA (negative selection) and unbound DNA (positive selection) [37, 38]. Alternatively, the homogeneous approach makes use of neutral polyacrylamide gel electrophoresis to separate bound and unbound fractions, instead of magnetic beads [39]. However, both strategies suffer from several shortcomings. On the one hand, immobilization of serum components seems a limiting strategy not only because the binding capacity of MBs but also because it restricts the targets to those containing functional groups that readily react with them. The lack of auxiliary reagents to activate the negatively-charged $-\mathrm{COOH}$ groups, low reactive at physiological $\mathrm{pH}$, imposes an additional not well understood restriction [37, 38]. Only in one case, depletion of major proteins is performed before indiscriminate immobilization of serum components on (MB) [38]. In fact, control experiments with an unrelated aptamer (selected against E. coli.) show significant binding to cancer serum components, raising questions about the tumor specificity of the aptamer and the identity of the target. On the other hand, the proposed homogeneous SELEX complicates the separation of bound fractions [39]. Although pioneering, this SELEX approach has certain weaknesses. Despite tumors from distinct organs share biomarkers, sera from patients with different types of cancer were not used in negative selection steps. Counterintuitively, the obtained aptamers using serum from gastric cancer showed selectivity against other cancers (lung, colorectal or hepatocellular) even though among the MS-assigned candidate targets are molecules present in several cancers [37]. Some of the aptamers derived in serum show promising clinical performance in 
hepatocellular cancer, but more strict studies in patients with other types of cancer are needed [39].

In the above described SELEX, the abnormal components of the serum are the targets. Beyond this application, human serum can be used to mimic the real environment. In an early attempt, simulated trypsinized human plasma (25\%) was used to isolate aptamers to be employed in MB-pull down prior to MS. When the aptamer was tested in human serum samples, the binding buffer required supplementation with EDTA to chelate divalent ions in order to allow the correct folding of the aptamer [40], showing an iondependent functioning of the selected aptamer. This is a typical example of the need for exact matching the selection milieu.

Post-operative samples as a source of targets for aptamer selection are also of great interest. The protein expression in tumor cell cultures might be different from that in primary tumor tissues, thus aptamers generated through classic Cell-SELEX might not achieve the analytical requirements to be applied in clinical specimens. With this idea in mind, Zamay et al. developed aptamers to lung adenocarcinoma cells derived from postoperative tissues, using lymphocytes and normal lung cells in the negative selections [41]. The cancer variability is addressed because each round is performed with fresh samples from different patients. The aptamers selected after 11 rounds bind to various candidate proteins identified by HPLC-HR-MS based on probability scoring. In support of this approach, these aptamers recognize the targets on CTCs and extracellular vesicles in peripheral blood of lung cancer patients, while they only weakly bind to cancer culture cells. The weak point is the need for a precise coordination between surgeons and laboratory teams, effort which is not always at hand. One of the aptamers was finally used for magnetic isolation of targets from crude blood plasma samples and 
for their subsequent electrochemical quantification, allowing to observe significant differences between healthy and cancer patients [42].

Similarly to post-operative samples, tissue slides have been employed to develop aptamers [43-46]. A remarkable advantage of tissue sections is that they are more representative of the cancer morphology than cultured cell lines, thus allowing the evolution of aptamers against different histological sections, including the extracellular matrix, the membrane components, and intracellular targets [43, 46]. Image-guided selection of aptamers that bind to tumor vasculature or tumor cells but not to stromal cells has been achieved using a laser beam to cut the region of interest [44]. Recently, an automatic microfluidic system has reduced the selection time to $15 \mathrm{~h}$ [45]. A possible drawback of tissue-SELEX is that the process of tissue slicing, immobilization, and staining with chemical reagents might lead to the denaturation of the target proteins on the tissue slide [36].

Other alternative routes to obtain aptamers in unpurified biological media include in vivo SELEX, which consists of the selection of aptamers able to specifically bind tumors in living animals [47-51]. Such methods rely on the direct injection of the nucleic acid library into the animal and the extraction of the target tissue after binding, which abolishes one of the most attractive characteristics of these receptors: animal-free selection. These approaches also require modified oligonucleotides to skip the nuclease degradation and are mostly aimed at the development of aptamers for targeted-drug delivery, and so are beyond the scope of this review.

\section{Electrochemical aptasensors for protein tumor biomarkers}

In general, aptamer selection against tumor biomarkers is performed in "biological" buffers, namely phosphate buffer saline and then tested in body fluids. Most of the 
electrochemical aptasensors have been tested in blood fractions because it is also the most tested body fluid in hospitals and there is reliable information on the clinical performance. Urine $[52,53]$ and recently saliva [54] are slowly appearing as alternative samples, though they are fully non-invasive and easy to collect from healthy individuals.

There are still many cases where only artificially spiked samples were tested. Though it is a step toward real applications, accessibility to clinical samples should be compulsory to draw accurate conclusions. Currently, there are aptamers selected against FDAapproved biomarkers such as alpha-fetoprotein (AFP) [55, 56], PSA [57-61], carcinoembryonic antigen (CEA) [62-69], HER2/neu [70, 71] or carbohydrate antigen 125 (CA125) [72-74]; and potential cancer biomarkers such as mucin 1 (MUC1) [62], neuron specific enolase (NSE) [67], osteopontin [75], vascular endothelial growth factor $\left(\mathrm{VEGF}_{165}\right)[76,77]$, platelet-derived growth factor (PDGF) $[52,53]$, epidermal growth factor receptor (EGFR) [78] and interleukin-6 (IL-6) [54].

Even aptamers against unknown targets are starting to be applied. This is the case of a direct aptasensor for the detection of lung cancer-related proteins [42]. In this case, the standards for calibration are purified proteins using streptavidin MB from blood of lung cancer patients eluted in urea. This means that the aptamer is able to recognize the denatured protein target. The aptamer whose sequence, including the primers, is 5'-CTC CTC TGA CTG TAA CCA CGT GCC CGA ACG CGA GTT GAG TTC CGA GAG CTC CGA CTT CTT GCA TAG GTA GTC CAG AAG CC-3' is stable in contact with crude plasma samples up to $5 \mathrm{~h}$ due to the preincubation of the aptamer-modified $\mathrm{Au}$ electrode with masking DNA [42].

When the target is predefined, purified native or recombinant proteins are used during the SELEX. In the case of MUC1, highly expressed by the majority of human 
adenocarcinomas and indicating a poor survival ratio, several types of recombinant proteins were used as targets $[79,80]$, which yielded a set of aptamers. The one with the sequence 5'- GCA GTT GAT CCT TTG GAT ACC CTG G-3' was applied to detect the protein shed to the bloodstream [62] but also to isolate CTCs (see section 4).

It has been argued that RNA aptamers are better suited for binding due to conformational diversity but, for analytical applications, DNA aptamers are superior and preferred because they are less prone to nuclease degradation. Importantly, direct translation of an RNA sequence to obtain the DNA counterpart able to bind the same target does not work $[16,34]$. The absence of 2'-OH groups strongly affects the recognition ability so the resultant aptamer is not functional. SELEX using DNA or RNA libraries selects sequences completely different, though the enrichment process depends on additional designing factors. As an example, Meirinho et al. used an RNA aptamer previously described to bind human recombinant osteopontin (5'-CGG CCA CAG AAU GAA AAA CCU CAU CGA UGU UGC AUA GUU G-3') [81] with precautions to avoid degradation. Contrarily to the original aptamer, it was not synthesized with 2'-OMe cytosine and uracyl nucleotides and therefore it was only applied in buffer solutions [82]. The analytical application in serum samples required a new selection from a DNA library against the recombinant human protein. The winning sequence (5'-TGT GTG CGG CAC TCC AGT CTG TTA CGC CGC-3') does not match the RNA one [75].

Most aptasensors use the thiol-Au chemistry to anchor an aptamer on the transducer. The stability of these mixed self-assembled monolayers (SAMs) is shorter than a month $[57,83]$ limiting the potential commercialization. Ternary SAMs have been reported to triplicate stability at least in genosensors [84] but they have not been widely adopted. Paper-based aptamer-containing devices showed superior stability than mixed SAMs, 
though they also rely on AuNPs for immobilization [67]. Of note, 96.7\% of signal remains after 4 weeks, higher percentage than using an antibody in an identical sensor layer, showing the improved stability of synthetic receptors.

Magnetic beads-based assays are appealing because of the compatibility with automation/microfluidics widely used in clinical labs. In one aptasensor for CEA using a 18-nt long aptamer (in italics) elongated to form a hairpin (5'-CCA CGA TAC CAG CTT ATT CAA TTC GTG G-3'), the streptavidin-modified MBs were used to entrap the biotinylated aptamer-CEA complex formed on Janus nanoparticles. The biotin tag was only accessible after recognition due to aptamer conformational switching [63]. However, the calibration by single standard additions complicates its clinical applicability. Another strategy is tethering the CEA aptamer to the MB by amidecoupling [66].

Biosensors require the receptor is in intimate contact with the transducer. An extended but not recommended trend includes under this definition homogeneous assays where the electrode is only used to measure the redox activity of a soluble probe. In a typical example of those, the transduction is achieved after a highly complicated recycling scheme (Figure 2A). It involves the digestion of a methylene blue-tagged DNA, which ultimately adsorbs on the graphene/GCE electrode and provides the analytical signal. The 18-nt CEA aptamer is designed as a hairpin structure that is opened only in the presence of the target [68].

The dominant assay format is the direct detection with a single aptamer. Depending on the interrogating technique the analytical signal can increase or decrease when the target concentration increases. Increasing analytical signals are preferred because they are less prone to false positive results when the sensor platform is degraded. When impedance is measured, protein binding to aptamer tethered to the transducer surface usually yields 
"signal-on" methods (Figure 2B). The detection of VEGF 165 with the aptamer 5'-TTT CCC GTC TTC CAG ACA AGA GTG CAG GG-3' chemisorbed on Au-based nanostructures is an example [76, 77]. The former sensor was also used in "signal-off" mode by measuring the current of an electroactive molecule that binds to the aptamer being displaced after protein recognition (Figure 2B). Similarly, other "signal-off" approaches add redox probes in solution to measure their accessibility to the sensor surface that is usually impeded after protein recognition $[55,57,75,76]$. To further decrease the electroactive surface area, the addition as blockers of hydrophobic beads specific for high molecular weight proteins was reported to enhance the sensitivity of a direct assay for lung cancer-related proteins by two orders of magnitude [42]. Attachment of the redox probe to the sensor layer makes the addition of any external reagents unnecessary [59, 67]. For point-of-care (POC) applications, reagentless methods are desirable. To this aim the use of self-reporting strands is the ideal strategy. This requires that the aptamer structural switching, upon binding, brings the distalappended redox label close to the electrode surface. Plaxco's group pioneers this sensor architecture and applied it to PDGF detection, but in undiluted serum the detectability resulted significantly reduced [85]. This strategy is not of general application because it requires a large conformational change, which is not always experienced by the aptamers selected under affinity pressure rather than proper folding for sensing. Besides, the LOD, defined by the total number of self-reporting aptamers on the surface, does not reach those of conventional ELISA. Likewise, it is not easily coupled to amplification schemes [86]. Nonetheless, this strategy is valuable for real-time detection of small molecules in body fluids [87], where weak aptamer-ligand binding makes this interaction reversible. 
Sandwich approaches are scarce in spite of the outcome of SELEX process being a collection of high-affinity binders. However, the candidates must bind different sites, which require additional screening experiments unless two identical binding sites exist. Aptamer truncation to the minimal length with the highest affinity is a post-SELEX time-consuming, and costly work carried out through trial and error experiments or more recently guided by molecular dynamics [88, 89]. Nonetheless, it is vividly recommended to minimize undesired hybridization events between a pair of receptors in sandwich formats and for economic reasons of the final device. CEA aptamers, for example, contain after truncation of the original library just 18-nt (the above cited) and 19 nt (5'- AGG GGG TGA AGG GAT ACC C-3'), half the commonest length [65]. Recently, PSA aptamer candidates for a sandwich approach were scrutinized for hybridization ability to minimize unspecific signals [61] (Figure 3A). The case of PDGF-BB, one of the isoforms of the PDGF implicated in the cell transformation process and in tumor growth and progression, is special because it is a homodimer. Curiously, the original SELEX was performed against a recombinant PDGF-AB to obtain aptamers that bind to the A chain but all screened aptamers exhibited preferential binding to the B chain in spite of a $60 \%$ homology between them [90]. Sandwich approaches with the aptamer that way obtained, 5'-CAG GCT ACG GCA CGT AGA GCA TCA CCA TGA TCC TG-3', are straightforward [52].

The need for high affinity aptamers is demonstrated in a sandwich aptasensor for HER2 protein. Direct replacement of one or two anti-HER-2/neu antibodies with aptamers rendered lower sensitivity due to lower in-solution aptamer affinity or availability of proper binding sites, although the limit of detection (LOD) was not affected [70]. The aptamer used is a trimeric version of the original 14nt-long aptamer 5'-GCA GCG GTG TGG GG-3', selected against a purified HER-2 protein from gastric cancer cells [91]. 
The monomeric aptamer was also employed in a peptide-aptamer sandwich assay [71]. It was extended with a toehold sequence that served as initiator of a self-assembled hybridization chain reaction. This aptasensor was tested in $\mathrm{HER}^{+}{ }^{+}$and HER2 ${ }^{-}$breast cancer patients and also after surgery corroborating with the postoperative decrease in the biomarker level recorded with an ELISA method.

Mixed antibody-aptamer assays bypass the hybridization issue, usually with aptamer acting as the signaling receptor. This format extends the amplification schemes to those based on molecular biology tools. Six-fold increase in signal and 500-fold lower LOD for CEA, a biomarker for several cancers, were achieved using a DNA isothermal amplification scheme, Rolling Circle Amplification (RCA), and the 18-nt aptamer sequence [69]. Hybridization chain reaction (HCR) that consists of a supersandwich extension through two assisting DNA strands, also improved the detection of CA-125, a glycoprotein elevated in ovarian cancer. In this approach, the aptamer 5'- TAA TAC GAC TCA CTA TAG GGA GAC AAG AAT AAA CGC TCA A-3' was used and the amplification power of HCR was increased by a branching growth on AuNPs [72] (Figure 3B). The way of selection of this sequence as well as of other aptamers for this biomarker (e.g. 5'-TTA TCG TAC GAC AGT CAT CCT ACA C-3') used in electrochemical approaches $[73,74]$ is not declared.

More rarely, aptamers act as capture elements while antibodies are the detection receptors. This scheme has been evaluated in a EGFR sensor. In this case a biotinylated aptamer anchored to streptavidin-MB recognized EGFR, and the AuNPs covered with the corresponding antibody served for recognition and as a reporter after dissolution of $\mathrm{Au}$ in acid [78]. Interestingly, this is one of the few examples of an RNA aptamer with an untruncated, unusually long sequence 5'-GGC GCU CCG ACC UUA GUC UCU GUG CCG CUA UAA UGC ACG GAU UUA AUC GCC GUA GAA AAG CAU 
GUC AAA GCC GGA ACC GUG UAG CAC AGC AGA-3'. Modification of the nucleobases routinely needed to preclude nuclease degradation was not used. Interestingly, one-week storage stability and capability to discriminate between serum from healthy and cancer patients is reported.

The ingenious amplification schemes affordable only with aptamers have reached noticeable LOD but increase the cost when enzymes (exonuclease strand recycling [68] or isothermal DNA amplification schemes [69]) or auxiliary strands (hybridizationbased displacement between aptamer and complementary DNA [62, 73], HCR [71, 72] or combination of both [66]) are needed. Likewise, the level of complexity increases requiring trained personnel to obtain reproducible results.

Multiplexing is a desirable characteristic of biosensors because there is increasing evidence pointing out that early detection of cancer needs panels of biomarkers to be simultaneously detected [92]. Dual aptasensors are emerging but only a few have been tested in clinical samples $[62,67]$.

Reusability, on the contrary, is not very common in clinical practice. Low-cost disposable biosensors are commonly claimed as advantageous but when thousands of analyses per month are performed the cost could become unaffordable. Reusable biosensors are not easy to obtain without damaging the sensor layer. An aptasensor for PSA claims easy regeneration by immersion in water at $70{ }^{\circ} \mathrm{C}$ for $1 \mathrm{~h}$ [57]. This temperature is high enough to disassemble the aptamer-target complex while maintaining the aptamer chemisorption on Au nanospears. The LOD of this aptasensor is well below the decision threshold for prostate cancer diagnosis. Taking into account that all healthy men have PSA content around this threshold, it is curios that serum from healthy people gave signals similar to blank samples (in buffer). One possible explanation is the use of serum from women but it was not specified. High temperatures 
are expected to disrupt the Au-thiol bond. Nonetheless, temperatures as high as $95{ }^{\circ} \mathrm{C}$ for $5 \mathrm{~min}$ did not show evidence of degradation of the sensor biolayer after 5 cycles of using a very long aptamer (5'-GTG ACG CTC CTA ACG CTG ACT CAG GTG CAG TTC TCG ACT CGG TCT TGA TGT GGG TCC TGT CCG TCC GAA CCA ATC-3’) for AFP detection, a tumor biomarker in use at diagnosis of hepatocellular carcinoma for disease staging [55].

An innovative approach for the detection of protein biomarkers through both the peptide and glycan regions has been first explored for PSA. The sandwich format uses the Savory's et al. protein binding aptamer 5'-AAT TAA AGC TCG CCA TCA AAT AGC-3' [93] to capture the protein and a glycan aptamer specifically derived for human PSA (5'-GGA CGG TTG CGC TAT ATT TAA CCA AAA GTC TGG ATT AAC A3') [61] to recognize the glycosylated region of the protein (Figure 3A). Both aptamers were selected in artificial buffers after exposure to the purified protein but the second one was deliberately directed towards the sugar moiety. Interestingly, when deployed in serum samples of patients with suspected prostate cancer, the aptasensor shows some discordant result with respect to the reference electrochemiluminescence method used in the hospital. Those punctual samples correspond to people with PSA content in the "gray zone" (inconclusive range because elevated PSA content could be ascribed to benign prostate conditions) or higher, who were finally diagnosed of something else. The aptasensor was able to correctly classify them pointing to superior discrimination. Nevertheless, the aptasensor should be tested in a larger cohort of serum samples to draw robust conclusions.

The main analytical features of the selected electrochemical approaches are summarized in Table 1. Of note, the analytical figures of merit are mostly obtained in buffer except in a few cases where the dynamic range and LOD is also explored in the body fluid. 
This information is essential in order not to overestimate the analytical performance in clinical settings and for validation. The effects on the analytical features vary depending on the type of sample, the transduction technique and the sensor architecture offering different antifouling degrees. The graphene-based FET demonstrated good resistance to fouling with similar performance in artificial gargle solutions and human saliva [54]. It is quite interesting to compare the effect of serum on two similar immobilization strategies: tethering the capture biotinylated aptamer to streptavidin covalently linked to a carboxylic SAM. One of the approaches, the sandwich aptasensor for PSA showed identical LOD in both media. The concentration range narrowed in serum due to the hook effect (signal decrease at high concentrations) that is shifted to smaller concentrations than in buffer [61]. In contrast, the osteopontin aptasensor showed worse LOD by $\mathrm{CV}$, but slightly lower by SWV. However, the regression equations lost linearity ( $r<0.95$ vs 0.9995 in buffer) [75]. The difference might be the length of the carboxylated alkanethiol chain; 3 carbons for the osteopontin sensor versus 11 for the PSA one, and the lack of passivating thiol in the former. Finally, an interesting case is detection of using Janus nanoparticles and MBs. It shows a three-fold loss in sensitivity that worsens the LOD, although the sample is not in contact with the transducer, which is considered favorable to minimize unspecific signals, and a high dilution of the serum is carried out (1:100). The assay still covers the clinical range [63].

In general, the number of samples tested are rather limited (from $1[63,75,77]$ to 21 [59]). Validation with other routine methods is not always presented and when it is estimated as trueness (bias), it ranges between 2\% [58] and 18 [76]- 23\% [57].

\section{Electrochemical aptasensors for CTCs}


Circulating tumor cells (CTCs) are cells detached from primary tumors that enter the bloodstream or the lymphatic system, where they invade distant sites of the body and form metastatic tumors, eventually giving rise to cancer-associated deaths [94]. They are considered as "treasure chests" because harbor proteins and nucleic acids that provide unique information about the tumor. Therefore, the role of CTCs as minimally invasive cancer biomarkers would be twofold. Their concentration is meaningful for cancer prognosis and treatment monitoring; while their cargo carries valuable information to facilitate the implementation of personalized therapy.

Despite their promising applications in cancer management, the rare occurrence of CTCs in blood (1-100 CTCs among billions of healthy blood cells in $1 \mathrm{~mL}$ of whole blood is clinically significant) along with the limited blood sample volume available ( 5-10 $\mathrm{mL})$ hampers their sensitive and specific detection. In consequence, prior to CTC analysis, they are usually captured and preconcentrated. There is a plethora of methods for CTC isolation [95] that could be roughly divided into two large groups. The first one comprises traditional methods based on physical properties of tumor cells such as size, density, electrical charge and deformability. Although intact CTCs are recovered in a cost-effective way, they suffer from limited purity as a result of their low selective isolation. The second group encompasses those methods based on biological features, namely on the affinity binding of specific antigens present on the surface of CTCs. To this group belongs CellSearch $\AA$, the only commercial product approved by the US Food and Drug Administration for CTC detection. It relies on immunomagnetic capture of CTCs of epithelial origin by using an anti-EpCAM antibody attached to magnetic particles. However, some CTCs might scape isolation due to dynamic changes in tumor cells such as epithelial-mesenchymal transition. 
Being functional nucleic acids obtained by chemical synthesis, aptamers possess intrinsic features that make them a better choice for specific separation and release of CTCs. Particularly interesting are their small size, high thermal and chemical stability, and easy modification with functional groups for efficient isolation of CTCs. Likewise, the release of captured CTCs while keeping cells viability could be carried out by reversible thermal disruption of affinity binding or nuclease cleavage, among other strategies [96]. Table 2 describes the distinctive features of the aptamer-based assays for CTCs detection in body fluids. Of note, all analytical characteristics were obtained in buffer.

The aptamer most commonly used for the design of electrochemical aptamer-based cytoassays is an aptamer against EpCAM, a transmembrane glycoprotein exclusively expressed in epithelial cells and epithelial derived neoplasm. This is a 48-nt DNA sequence so-called SYL3C (5'-CAC TAC AGA GGT TGC GTC TGT CCC ACG TTG TCA TGG GGG GTT GGC CTG-3'), obtained by a SELEX process which uses the purified recombinant protein as the target [97], but it has been proven to recognize EpCAM both on cell surfaces and exosomes. Direct recognition of breast cancer cell line MCF-7 is possible [98] as well as in combination with antibody [99] or a glycanbinding protein [100], which indicates different binding sites for aptamer and antibody on the protein moiety and lack of affinity for the sugar region.

CTCs usually carry more than one of the target proteins, which make sandwich approaches more frequently designed than in the case of free protein detection. The 25nt-long MUC1 aptamer above mentioned acted as capturing and signaling receptor to detect MCF-7 cell line in spiked serum [101] and blood [102].

Aptamers for CTC detection are not limited to those raised against purified proteins. When searching for discriminating features between normal and tumor cells, Cell- 
SELEX-derived aptamers are of great utility. Aptamers specific of leukemia cells (CCRF-CEM) were obtained by using a Burkitt's lymphoma cell line (Ramos cells) as negative control [103]. Optimization of the best binders based on their secondary structure led to a 41-nt long aptamer named sgc8c (5'-ATC TAA CTG CTG CGC CGC CGG GAA AAT ACT GTA CGG TTA GA-3') [104], widely used in aptasensing. Specifically, electrochemical aptassays were applied to CCRF-CEM added to serum samples [105-107] or clinical samples from patients [108]. The target of sgc8c aptamer turned out to be PTK7-5, an isoform of protein tyrosine kinase 7 [109]. Selective recognition of Burkitt's lymphoma cells can be also achieved with a 44-nt aptamer TD05 (5'-ACC GGG AGG ATA GTT CGG TGG CTG TTC AGG GTC TCC TCC CGG TG-3') with immunoglobulin heavy $\mathrm{Mu}$ chain (IGMN) as binding site [35]. Despite omitting the counter selection step in Cell-SELEX process, cytoassays based on TD05 aptamer showed specific binding to Ramos cells in the presence of breast (MCF-7 and SK-BR-3), lung (A549) and leukemia (CCRF-CEM) cancer cell lines [108].

A panel of aptamers has been selected to detect CTCs derived from liver cancer, among which TLS1c (5'-ACA GGA GTG ATG GTT GTT ATC TGG CCT CAG AGG TTC TCG GGT GTG GTC ACT CCT G-3') and TLS11a (5'-ACA GCA TCC CCA TGT GAA CAA TCG CAT TGT GAT TGT TAC GGT TTC CGC CTC ATG GAC GTG CTG-3') stand out for their high affinity. They have been used separately [110] or combined [111].

The G-quadruplex forming DNA aptamer (5'-GGT GGT GGT GGT TGT GGT GGT GGT GG-3') known as AS1411 targeting nucleolin protein has been used in electrochemical sensors directed to different cancer cells: breast (MCF-7 and MB231) lung (A549), and cervical (HeLa) [102, 112]. This aptamer has advanced up to clinical 
trial phase II for acute myeloid leukemia treatment but Antisoma, the proprietary company, terminated it due to inconclusive results.

Chemisorption on $\mathrm{Au}$ surfaces is the dominant surface chemistry to attach the aptamer to the transducer. To maximize the accessibility of capture aptamers and thus, the target binding capability, DNA nanotetrahedron (NTH) structures are used as efficient bioscaffolds $[102,110]$. Alternatively, the binding site of the aptamer can be extended away from the surface with an extra 19-nt long fragment for partial hybridization of the aptamer with a surface-tethered complementary probe [98]; this approach favors the reutilization of the aptasensor while circumventing surface steric hindrance. This is also achieved by elongation of the aptamer sequence at the proximal end to carbon surfaces, e.g. with 15 extra thymines [111]. Carbodiimide-mediated attachment of aminefunctionalized aptamers to carbon surfaces with carboxylic acid groups is also a simple strategy $[111,112]$.

To increase the number of receptors anchored to the electrode surface, and thus the device sensitivity, as well as speeding up the electron transfer between the redox molecule and the electrode, conducting nanomaterials such as porous graphene oxide [112] or reduce graphene oxide decorated with gold nanoparticles [101] are extremely useful.

Furthermore, capturing CTCs with aptamer-modified MB [99, 100] or magnetic nanocarriers [108] and subsequent detection onto an electronic surface can provide superior analytical performances because both steps are carried out under their own optimal conditions. These approaches cannot be considered as genuine aptasensors because the biorecognition event does not take place on the transducer [113].

Regarding the assay format, direct aptassays involve the molecular recognition of the target cancer cells using the cognate aptamer immobilized onto the sensing interface 
(Figure 4). Using impedance as a non-destructive non-passivating detection technique, the signal-on approach to quantify EpCAM ${ }^{+}$tumor cells enabled the efficient recovery of culturable cancer cells by enzymatic cleavage of several uracil bases in the aptamer sequence [98] (Figure 4A). That way, the cells can be employed in downstream applications and the electrodes are reusable.

Among "signal-off" approaches, the decrease in the oxidation current of ascorbic acid was employed to detect leukemia cells, boosted about 20 times upon localized surface plasmon resonance excitation [105]. This amplification strategy led to a LOD of 5 cells $\mathrm{mL}^{-1}$ as well as a wide linear response range, although tedious pretreatment of blood samples is required. Another interesting "signal-off" approach involves a light addressable potentiometric sensor (LAPS) based on a $\mathrm{Si}_{3} \mathrm{~N}_{4}-\mathrm{SiO}_{2}-\mathrm{Si}$ n type structure modified with porous graphene oxide for increasing the active sensing area [112]. Despite a modest detection limit, it provides results in good agreement with cancer staging. Direct recognition of CTCs was also carried out with the aptamer receptor immobilized onto an array nanochannel-ion channel hybrid by recording the drop-off in the ionic flow through the nanochannels. Although its clinical application remains to be demonstrated, release of viable CTCs was achieved by endonuclease digestion, thus promoting subsequent genomic and proteomic studies [107] (Figure 4B).

Compared to the previous single-receptor approaches, sandwich assays usually provide enhanced selectivity due to the participation of a pair of receptors (capture and reporter ones). Likewise, they favor a great variety of amplification strategies, which can be classified into two large groups: (i) those based on the oligonucleotide nature of synthetic receptors and (ii) those based on the unique advantages of nanoparticles (Figure 5). 
Beyond DNA amplification strategies relying on the extension of the reporter aptamer with a proper primer thus triggering isothermal and linear RCA [99, 110], nucleic acid nanomachines such as DNA walkers have finally found analytical interest to improve aptassay sensitivity [106] (Figure 5A). However, their sophisticated design involving DNA-modifying enzymes along with strand displacement reactions hampers its general applicability in clinical settings by the moment.

Nanoparticles are versatile tools for signal amplification. As nanocarriers, nanoparticles can load multiple units of electroactive species (ferrocene or thionine) [108] (Figure 5B), or HRP-mimicking DNAzymes [102] (Figure 5C) per recognition event that, in combination with sandwich electrochemical aptassays, gave rise to good analytical performance, although it is true that the presence of natural HRP is still needed. There is also a clear trend to replace natural redox enzymes by catalytic nanomaterials as reporter molecules. In this regard, $\mathrm{CuO}$ [101] (Figure 5D) and $\mathrm{Pd} @ \mathrm{Au}$ nanoparticles [100] exhibit hydrogen peroxide reduction activity. Beyond an improved stability against temperature and $\mathrm{pH}$ changes, their peroxidase activity is lower than that of the natural counterpart.

Antifouling strategies such as a previous blocking step with a solution containing healthy blood cells have been reported when interrogating blood samples [111] even though two types of aptamers were used to detect a single type of CTCs.

\section{Electrochemical aptasensors for exosomes}

Cancer-derived exosomes constitute another attractive target for potential diagnostics, prognostics and surveillance of the disease. Exosomes are a kind of extracellular vesicles with a size in the range $30-150 \mathrm{~nm}$ in diameter, which transmit molecular messengers between cells, thus contributing to the sustained growth, invasion and 
metastasis of cancer cells [114]. They have their origin in the fusion of internal vesicles with the plasma membrane to be released from parent cells to the extracellular fluid, moving to adjacent areas or tissues. Consequently, they are present in different body fluids including blood, urine, cerebrospinal fluid, saliva or breast milk, where they carry diverse molecules that are characteristic of the parent cell. Although exosomes have been discovered in the $80 \mathrm{~s}$, a recent flurry of work has shown that they hold great potential in cancer liquid biopsy [115].

This new class of circulating cancer biomarkers is more abundant than CTCs, and is relatively stable. The exosomal cargos, such as oncoproteins, RNA and DNA fragments, provide information about the primary tumor and its environment in a minimally invasive way. In addition, as cancer cells secrete more exosomes than their nonmalignant counterparts, the selective counting of cancer-specific exosomes offers valuable information for diagnosis. Despite the potential advantages of using exosomes as biomarkers listed above, their nanometric size poses important technical challenges for clinical translation. The majority of existing technologies for exosome detection and quantification require a previous isolation and enrichment step, which is typically accomplished by ultracentrifugation, ultrafiltration, polymer precipitation or immunoaffinity purification [116]. Nanoparticle tracking analysis (NTA) is the most popular technique for obtaining information about the size and concentration of exosomes after their isolation [117]. This is a light-scattering technique, only based on a physical property of exosomes, and in consequence it cannot support differentiation of phenotypes and subpopulations of the extracellular vesicles.

To improve the selectivity of detection, it is necessary to select exosome-specific surface markers which would direct the selective capture and detection. Among the components of membrane exosomes there are clusters of tetraspanins, a family of 
membrane proteins also referred as the transmembrane 4 superfamily proteins, which include CD9, CD63 or CD81, together with adhesion molecules such as integrins or the epithelial cell adhesion molecule (EpCAM) [114]. These surface proteins are typically caught by specific antibodies to selectively capture and detect the exosomes.

Although the use of aptamers for the integration of capture and recognition of the extracellular vesicles is less than 5 year-old, examples of electrochemical aptamerbased-sensors and assays for exosomes are compelling and growing.

The most widely employed aptamer so far for the design of electrochemical aptamerbased assays for exosomes is an aptamer against CD63 [118-125], a member of tetraspanin family and a type III lysosomal membrane protein that is a classic marker for exosomes. This is a 32-nt aptamer developed by Base Pair Biotechnologies [126], with the sequence: 5'-CAC CCC ACC TCG CTC CCG TGA CAC TAA TGC TA-3'. A truncated version of this aptamer, with just 10nt from the 5 '-terminus, has proven effective for CD63 recognition [124]. As CD63 is presented in different types of exosomes, the corresponding aptamer has been employed for the capture or detection of exosomes secreted by different cancer cells such as breast (MCF-7) [118-122] and liver (HepG2) [123-125] cell lines. No information is available about the target used in the selection process or the affinity of it. Another ubiquitously expressed cancer-biomarker is EpCAM, whose 48-bases long aptamer mentioned above is also suitable for binding to exosomes released by, for example, breast $[118,119]$ or prostate [127] cancer cells. The MUC1 aptamer 5'-TAC TGC ATG CAC ACC ACT TCA ACT A-3', selected in buffer against a recombinant form different from the protein employed for selecting the aptamer used in serum and CTCs [80], has served for the selective detection of exosomes from gastric cancer cells in combination with antibodies anti-CD63 for capturing [128]. 
It is possible to improve the selectivity of the detection by selecting as a target a cancerspecific marker on the surface of exosomes. This is the case of prostate specific membrane antigen (PSMA), which is an exopeptidase overexpressed on the apical plasma membrane of prostate cancer cells. The DNA aptamer with the sequence: $5^{\prime}-$ GCG TTT TCG CTT TTG CGT TTT GGG TCA TCT GCT TAC GAT AGC AAT GCT-3' has been explored for the direct detection of exosomes associated to prostate cancer [127] or indirectly by measuring the release of an auxiliary cDNA that hybridized on the electrode [129].

To preclude binding to normal cell features, Cell-SELEX is a useful source of aptamers for exosomes. This was the approach followed to select an aptamer against tumor liver cells, LZH8: 5'-ATC CAG AGT GAC GCA GCA TAT TAG TAC GGC TTA ACC CPC ATG GTG GAC ACG GTG GCT TAG T. In addition, two artificial nucleotides Z and $\mathrm{P}$ were introduced in the initial library in order to improve the probability of selecting the best binder. The nucleobases form three hydrogen bonds and do not disturb the Watson-Crick double helix so they are compatible with polymerases [130]. Considering the homology between the membrane proteins of cells and secreted exosomes, this aptamer also exhibits selectivity for exosomes secreted by hepatocarcinoma cells (HepG2), discriminating them from those released by noncancerous liver cells (Hu1545), and in consequence it is an efficient receptor for the quantification of exosomes [131].

The development of aptamer-based electrochemical sensors requires attaching the aptamer to the transducer, and then measure of an electrical property directly or indirectly related to changes occurring when the exosomes are captured. To date, exosome aptasensors have been mainly fabricated by using gold surfaces, where aptamers are chemisorbed through thiol groups $[121,125,127,131]$ or using $\mathrm{NH}_{2}$ - 
modified aptamers covalently linked to surfaces bearing carboxyl groups [118, 122]. The complex composition of human fluids and the low abundance of exosomes in these samples, make the direct integration of selective recognition and detection not an easy task. A way to overcome this problem is to apply modified MB for exosome separation and enrichment, coupled to the downstream detection of the binding event. These have been accomplished by immobilizing onto MB not only aptamers (CD63-aptamer [119] or PSMA aptamer [129]) but also specific antibodies, for example antibodies recognizing CD63 protein [123] or other proteins specifically binding molecules on the surface of exosomes such as phosphatidylserine binding-protein (Tim 4) [124]. While these detection schemes cannot be strictly considered aptasensors, it is possible to integrate both steps in a microfluidic platform to analyze in a rapid and simple way exosomes in clinical specimens for cancer diagnosis [124].

Electrochemical assays for exosome detection also fall into two classes i.e. direct and sandwich assays. The first relies on the capture of exosomes by a single immobilized specific aptamer. The simplest "signal-off" approach uses the electron-transfer suppression of a soluble ferro/ferricyanide probe [131] (Figure 6A). In this device, an oriented immobilization of the aptamer on Au and smart spacing, through a tetrahedral DNA nanostructure, improves the accessibility of exosomes to the recognition element and in consequence the sensitivity of the assay, reporting an LOD 100-fold lower than the obtained with a classical SAM for the immobilization of the aptamer. Despite the impressive sensitivity without any amplification strategy, the sensor was not challenged in real samples, where probably the complexity of the matrix would lead to unspecific adsorption and signal suppression (false positive). Displacement assays involve the immobilization of the aptamer in the form of a duplex, hybridized with one or more antisense DNA strands (Figure 6B) $[125,129]$. The recognition of exosomes causes the 
release of the complementary strands that are detected. It is very important to design the hybridizing strands to be complementary to the aptamer in the region that is directly involved in the recognition of the target. When the displaced strand is labelled with an electroactive molecule, for example methylene blue, the recognition event produces a decrease in the voltammetric signal of the marker, which is related to the exosome concentration (secreted by liver cancer cells in the example) [125]. Another strand displacement approach for the detection of exosomes from prostate cancer cells needed 3 cDNA strands, so the design is even more challenging [129]. The recognition event takes place on the surface of MBs whereas the released DNA is detected by an exonuclease III-assisted target recycling scheme on a separate gold electrode. A decrease in the voltammetric signal ascribed to the soluble redox reporter, $\mathrm{Ru}\left(\mathrm{NH}_{3}\right)_{6}{ }^{3+}$, leads to a LOD surprisingly higher than the simplest design above mentioned [131], despite the double-amplification process. The direct recognition of exosomes can also be transformed into a DNA detection assay by derivatizing the exosomes, once entrapped on the sensing layer, with a ssDNA sequence by a click chemistry process, for example, where azide-labelled oligonucleotides are linked to alkynyl-4-onemodified exosomes [121]. The ssDNA is then detected by HCR, using a biotin-hairpin as a probe (Figure 6C). The final detection of the elongated DNA products is achieved by electrochemically measuring the peroxidase activity of the streptavidin-peroxidase conjugate used as a reporter. This is a very complicated scheme, which demands a long derivatization process after exosome capturing, and although it has proven useful for discriminating one breast cancer patient from one healthy individual, the design suffers from a relatively poor LOD when compared with simpler assays.

The strategies described above make use of a heterogeneous reaction between immobilized aptamers and exosomes, but the recognition reaction may also take place 
in solution (homogeneous assay). The capture aptamer is hybridized with an oligonucleotide, which is released upon exosome binding. These strands are detected on an ITO electrode, using doxorubicin as an electroactive probe, by an exonuclease IIIassisted recycling assay [120]. The design has the advantage of improving the binding efficiency of the exosomes, thus leading to improved detectability, although it has been only tested in spiked serum samples.

Selectivity of the above designs is based exclusively on the selectivity of a single aptamer used as a recognition element. To overcome this problem, sandwich-type assays using a pair of aptamers as a capture and reporting receptor [118, 119, 122, 127] or alternatively, an antibody [123, 128] or a surface lipid binding-protein [124] as a capture element in combination with a reporting aptamer, have been developed (Figure 7). Different signal generation and amplification strategies have been employed in these assays, such as electrooxidation of metal nanoparticles linked to the reporting aptamer [127] (Figure 7A), catalytic effect of $\mathrm{Ti}_{3} \mathrm{C}_{2}$ MXenes nanosheets over electrochemiluminescence of luminol [118], peroxidase activity of the complex between hemin and a DNAzyme that elongates the aptamer $[122,124]$ (Figure 7C) and different nucleic acid-based amplification strategies such as exonuclease III-assisted recycling [119], cascade toehold-mediated strand displacement [123], and RCA [128] (Figure 7B). Table 3 summarizes the analytical performance of the published electrochemical aptamer-based assays for exosome detection. All analytical features were obtained in buffer, typically PBS, due to the need for isolation prior to detection. Integrated collection and detection has not been reported using aptamers as a capture element. An antibody-based electrochemical device has been designed to entrap salivary exosomes and disrupted them by an electrical field to release their cargo [132]. The nucleic acid content is then detected through hybridization with appropriate complementary probes 
anchored on a different electrode surface present in the chip. It is reasonable to envision similar approaches with aptamers instead of antibodies in the future.

Despite the inherent complexity associated with the use of nucleic acid amplification strategies for signal generation, these designs do not provide much better sensitivity. Up to date, the lowest LOD $\left(9.5 \times 10^{2}\right.$ particles $\left.\mathrm{mL}^{-1}\right)$ is achieved in combination with RCA, using an aptamer against MUC1 elongated with a primer sequence that is complementary to a circular padlock containing a G-quadruplex unit [128]. After recognition, RCA incorporates multiple G-quadruplex units that in the presence of hemin show peroxidase-like activity, leading to a large amplification of the voltammetric signal. However, the achieved LOD is very close to that obtained with copper and silver nanoparticles as labels: 50 particles per sensor, which corresponds to $2 \times 10^{3}$ particles $\mathrm{mL}^{-1}$ for a volume of sample of $25 \mu \mathrm{L}$ [127]. Both designs supported the detection of exosomes in serum samples, and proved to be efficient in the discrimination of healthy individuals from prostate cancer patients $(n=10)$ [127] or gastric cancer patients $(n=16)$ [128]. Other designs also tested in the analysis of serum samples from cancer patients, although in a fairly limited number, are linked to the use of a DNAzyme sequence as a label, and were evaluated in the diagnosis of breast cancer (8 patients) [122], and hepatic carcinoma (10 patients) [124].

\section{The long path from lab bench to the clinical market}

The previous sections evidence the significant advancements that researchers have made in the development of electrochemical aptasensors for cancer diagnosis. However, these devices have not yet fulfilled their potential to be translated to the clinical market, so that they can directly benefit patients. Challenges to take this great leap forward include: a) to identify more specific tumor targets and b) to rational design the SELEX protocols 
to obtain robust well-characterized aptamers for clinically significant biomarkers, c) to evaluate the clinical validity and utility of the new aptasensors, rather than simply their analytical performance, and d) to develop simplest and integrated platforms useful in POC systems.

a. More specific tumor targets for the selection of aptamers.

Cancer management requires collecting information about the disease stage and evolution. These data cannot be gathered from repeated biopsies. The search for specific biomarkers in the body fluids is emerging as a powerful tool, but their use as clinical markers needs for selective receptors with an extraordinary ability to discriminate minute changes within a defined target. Cancer is associated with a variety of aberrant features whose detection might be more clinically significant. The AFP-L3 test based on the ratio between the core-fucosylated protein and the whole protein is a successful example [133]. Specific lectins are used to detect the aberrant fucosylation ratio. Aptamers can replace them to recognize these or other subtle differences because they can reach superior affinity. A first example to demonstrate the high clinical selectivity that aptasensors might achieve in this direction is the discrepancies in PSA values obtained with the aptasandwich assay recognizing both the protein and the glycan moieties of PSA, and the reference method, just focused in the protein [61]. Nonetheless, this task will require exquisite accuracy because it is based on percentage changes for the aberrant form of the protein with respect to its total amount.

Future research should focus on novel biomarkers with enhanced sensitivity/selectivity rather than on well-known biomarkers. Test currently in use will not be replaced unless a substantial benefit from a clinical or economical point of view is apparent [134]. With this aim, close collaboration between experts in the biomedical and analytical fields is highly important. Interestingly, the use of affinity reagents different from the widely 
accepted antibodies has not demonstrated superior clinical specificity and sensitivity of the detection of the approved biomarkers. Protein-binding aptamers behave similar to antibodies in terms of affinity and selectivity, though the selection process of the latter can be tuned to boost both features. When the aptamer selection is targeting proteins on cell surface, the SELEX protocol should include several counter selections steps with numerous types of cells. Those essential steps to avoid cross-reactivity in the real application are rarely exploited. As a consequence, promiscuous aptamers binding several types of tumor cells through shared surface features are sometimes obtained [135]. Nonetheless, aptamers show benefits in reagent stability and in lowering the LOD through amplification schemes not amenable to antibodies. Extreme detectability might seem useless once the normal physiological level is reached, but it can lead to redefinition of the disease and clinical management [134].

Combination of several already described and novel biomarkers can unblock the unmet goal of early diagnosis of cancer and avoid confusion with biomarkers whose level also elevates with aging without implying enhanced cancer risk. This goal may be facilitated by the design of multiplexed aptasensors.

b. More aptamers in which we can trust

Another important question is the wide diversity in composition and properties of biological fluids, which should be considered in the design of the SELEX process. The proper aptamer recognition event is strongly dependent on the whole system: the aptamer sequence, the chemical nature of the target and the composition of the interrogating medium [34]. The best performance would require matching the selection conditions with the application to keep both the aptamer and target in their optimum chemical and structural conformations. The detailed inspection of aptamers used in clinical samples for cancer diagnostics reveals that the milieu in which they were 
derived is not as decisive as it is commonly accepted. When targeting free proteins, phosphate buffer saline sometimes supplemented with ions reasonably emulates the body fluids so that the aptamers can easily recognize their target in clinical samples. Good agreement with validated methods using different detection techniques further support this finding, though more extensive studies are needed before entering the commercial pipeline. It is worth noting that some of the aptamers mentioned above are among the oldest developed and they have been tested repeatedly in several labs using a variety of transduction techniques beyond electrochemistry. An exhaustive characterization of aptamers is central to secure adequate performance and diminish the risk of failure. Traceability of the aptamer back to the original selection is also important to trust in the good performance.

When the intended final use is to isolate/quantify CTCs or exosomes the selection of aptamers in crude media is more often to preserve the native target state with its inherent (aberrant) variants although the targets remain unidentified. This might facilitate the detection of rare subtypes of tumor cells that skip current identification. There is a clear need of expanding the collection of available aptamers against cancerspecific biomarkers on the surface of CTCs, for reliable discrimination between them and healthy blood cells. Furthermore, the use of multiple aptamers as ligands of several biomarkers would promote the efficient capture of CTC subpopulations. The design of multivalent capture devices is also a convenient option. AuNPs decorated with multiple units of the sgc8 aptamer [136] or long DNA "tentacles" comprising repeated aptamer sequences generated by RCA [137] have already demonstrated their high cell capture efficiency in comparison with single units.

c. Evaluation of the clinical validity and utility. 
When a laboratory assay faces an in-vitro medical test in specific clinical contexts, the excellence in analytical performance is taken for granted but clinical validity and utility must be demonstrated. Clinical validity (or performance) is the ability of the method to correctly classify patients with or without the disease or in a particular stage of it, while the clinical utility (or effectiveness) covers the health outcomes improvements. This includes patients' benefits and harms, as well as process outcomes, such as speeding up the time to diagnosis [134].

Within the economic evaluation, the cost per assay has an impact. Paper-based aptasensors claim a cost per assay below \$1 [67], but broader impacts are also considered. For example, for POC devices, implementation of biosensors can dramatically change the health organization system from large facilities to local units, which might be decisive to adopt the technology.

Integrated portable devices with wireless transmission of information to smartphones or cloud servers are useful to monitor the biomarker concentration trends and open the possibility to remote control by medical staff. Though a continuous monitoring of cancer biomarkers is not usually needed, this proposal can find applicability in order to reduce the inconvenience of attending doctor's office frequently. Recently, this type of device was reported for a cancer biomarker measured in saliva [54]. Companies like ApolloDx are developing electrochemical aptamer-based portable devices promising to detect cancer biomarkers though, up to date, they are only validated against infectious diseases [138].

d. Development of simple and integrated platforms for POC systems.

In POC simplicity is a must. Highly sensitive multistep protocols with amplification schemes, as those described, must demonstrate their reliability to be handled by untrained staff. One desirable feature of POC is the direct measurement in unpretreated 
samples: for example, whole blood drops in glucometers. None of the methods reported so far fulfill this need in blood. Most of them are applied to serum, meaning that pretreatment is needed. Even crude plasma samples required centrifugation and incubation steps [42]. Free protein detection in undiluted samples has been accomplished in a few methods $[59,62,67,73]$, while the rest requires from twice to ten-fold dilution, sometimes 100 -fold or higher to reach the working range or eliminate matrix effects from unspecific adsorption.

CTCs and exosomes detection require specific isolation making this step crucial for their accurate measurement. Integrated platforms based on microfluidics to isolate and detect these targets are emerging. Aptamer-based devices such as Nano Velcro have the ability to easily release the cells for downstream genetic and molecular profiling with a cost for CTC enumeration about $\$ 50$, in contrast to $\$ 1200$ estimated with CellSearch $^{\circledR}$ [139]. Heterogeneity of exosomes makes isolation a current challenge that would benefit from microfluidics and the future availability of sets of aptamers to confront the cancer evolution under different physiological stages of the disease.

If patent activity serves to forecast the position of a technology in the marketplace, the potential of aptamer field is strong. A general search on Patentscope [140], using aptamer as input, retrieves thousands of files. Beyond the initial patents on SELEX protocol and its variants, the main interest in filing a patent on aptamers is their therapeutic use. Nonetheless, diagnostic methods are also patented. Patent searching is a daunting task because of the plurality of names under which "aptamer" is hidden. Besides, the claims are extremely broad in order to encompass all variations of the method patented, which might include different kinds of capture elements [141-143] or a wide variety of targets [144] in the same patent file. Occasionally, the aptamer-based methods to detect cancer biomarkers do not include a specific transduction technique 
but any diagnostic kit that uses the specific sequence claimed [145]. Among the electrochemical techniques, impedance [146] or amperometry [147] stands out. ApolloDx have patented an electrochemical device based on the latter for wide diagnostic testing [147]. Interestingly, at least two patents claim devices to detect cancer biomarkers in saliva $[142,148]$. The above mentioned patents focused on protein targets. Recent patents claim the use of aptamers to capture extracellular vesicles from tissues [149] or all body fluids, provided that the individual is suspected to have any type of cancer [150]. Similarly, a microfluidic chip is claimed to capture CTCs by means of aptamers for cancer-screening purposes. The same patent proposes the eradication of malignant cells by injecting a photosensitizer-aptamer conjugate into the bloodstream and application of a laser beam that destroy them [151]. Roche Diagnostics Gmbh has recently filed a patent for a device to capture and analyze of CTCs. Besides of antibodies, one of the embodiments comprises the use of aptamers [152].

\section{Concluding remarks}

There is no doubt that the electrochemical aptasensor field has increased enormously and is now tackling the difficulties of shifting to the market. When using rigorously characterized aptamers, their properties along with continuously improved selection strategies indicate that there is no reason to expect delays in commercialization due to technical issues of the receptor. Nonetheless, fighting the successful and long history of antibodies, which are much more numerous than aptamers, is hard. Likewise, the ignorance of the aptamers and their capabilities among investors and clinicians cannot be set aside as an influencing factor that blocks the commercialization. We would like to emphasize that the aim is not to substitute or withdraw antibodies. On the contrary, the ultimate goal is to use aptamers in those applications where they outperform other 
affinity reagents and take advantages of their unique characteristics, such as animal-free selection. We believe that potential successful niches for aptamers might be targets that are inherently difficult targets for antibodies: low immunogenic compounds such as glycans, buried regions hard to access for large molecules or specific sites on molecules, e.g. aberrant modifications.

Electrochemical transduction should make easy the translation from the lab prototype to the marketable device. Antifouling strategies to protect against unspecific signals are extensively studied on a variety of electrode surfaces, but enhanced stability of the sensing layer is a weak point that needs to be addressed. As other biosensors relying on antibodies or other transduction techniques, the ultimate bottleneck in the commercial pipeline is providing evidences of clinical utility, in terms of both cost-effectiveness and patient and health system outcomes to convince stakeholders to invest in this young technology.

\section{Acknowledgements}

This work was supported by the Spanish Government (project RTI-2018-095756-B-I00) and Principado de Asturias Government (IDI2018-000217), co-financed by FEDER funds. A.D.F. thanks the Asociación Española Contra el Cáncer for a Ph.D. fellowship and R.L.G. thanks the Spanish Government for a predoctoral FPU grant (FPU16/05670). 
Table 1: Summary of analytical characteristics of published electrochemical aptamer-based assays for free protein detection

\begin{tabular}{|c|c|c|c|c|c|}
\hline Receptor & Sensing platform / Assay format & Detection method & Linear Range / LOD & $\begin{array}{c}\text { Sample } \\
\text { (number) }\end{array}$ & Ref \\
\hline AFP-aptamer & $\begin{array}{c}\text { Spindle-shaped Au nanostructures on } \\
\text { AuE / direct (signal off) }\end{array}$ & DPV of ferri/ferrocyanide & $\begin{array}{c}0.005-100 \mathrm{ng} \mathrm{mL}^{-1} / \\
0.23 \mathrm{pg} \mathrm{mL}^{-1}\end{array}$ & $\mathrm{~S}(20)$ & {$[55]$} \\
\hline AFP apt & $\mathrm{AuE} /$ direct & DPV of ferri/ferrocyanide & $\begin{array}{c}0.01-100 \mathrm{pg} \mathrm{mL}^{-1} / \\
3.1 \mathrm{fg} \mathrm{mL}^{-1}\end{array}$ & S (3) & {$[56]$} \\
\hline PSA apt & $\begin{array}{l}\text { Au nanospears }+\mathrm{AuE} \\
\text { / direct (signal off) }\end{array}$ & DPV of ferri/ferrocyanide & $\begin{array}{l}0.125-200 \mathrm{ng} \mathrm{mL}^{-1} / \\
50 \mathrm{pg} \mathrm{mL}^{-1}\end{array}$ & $\mathrm{~S}(10)$ & {$[57]$} \\
\hline PSA apt & rG /AuNPs/ MWCNT /GCE/ direct & $\begin{array}{c}\text { DPV of ferri/ferrocianyde (signal off) } \\
\text { EIS }\end{array}$ & $\begin{array}{l}0.005-20 \mathrm{ng} \mathrm{mL}^{-1} / 1 \mathrm{pg} \mathrm{mL}^{-1} \\
0.005-100 \mathrm{ng} \mathrm{mL}^{-1} / 1 \mathrm{pg} \mathrm{mL}^{-1}\end{array}$ & S (4) & {$[58]$} \\
\hline PSA apt & AuNPs/rGO/THI/ SPCE (signal off) & DPV of THI & $0.05-200 \mathrm{ng} \mathrm{mL}^{-1} / 10 \mathrm{pg} \mathrm{mL}^{-1}$ & $\mathrm{~S}(21)$ & {$[59]$} \\
\hline PSA apt & $\begin{array}{c}\text { round hairbrush-like } \mathrm{Au} \\
\text { nanostructure / direct }\end{array}$ & DPV of methylene blue & $\begin{array}{l}0.125-128 \mathrm{ng} \mathrm{mL}^{-1} / \\
50 \mathrm{pg} \mathrm{mL}^{-1}\end{array}$ & $\mathrm{~S}(10)$ & {$[60]$} \\
\hline $\begin{array}{l}\text { Capt: PSA apt } \\
\text { Sign:PSA-1 apt }\end{array}$ & Strep on AuE / sandwich & Chronoamperometry of TMB & $\begin{array}{c}0.66-62.5 \mathrm{ng} \mathrm{mL}^{-1} * * \text { in buffer } \\
0.66-25 \mathrm{ng} \mathrm{mL}^{-1} * * \text { in serum/ } \\
0.66 \mathrm{ng} \mathrm{mL}^{-1} \text { (both) }\end{array}$ & $\mathrm{S}(15)$ & {$[61]$} \\
\hline CEA apt hybridized to cDNA & AuE / strand displacement assay & DPV of metal ion labels $+\mathrm{Ru}\left(\mathrm{NH}_{3}\right)_{6}{ }^{3+}$ & $0.01 \mathrm{pM}-100 \mathrm{nM} / 3.33 \mathrm{fM}$ & S (5) & {$[62]$} \\
\hline CEA apt & $\mathrm{Au}-\mathrm{SiO}_{2}$ Janus NPs-CE / direct & Amperometry (enzyme amplification) & $\begin{array}{l}0.2-5000 \mathrm{ng} \mathrm{mL}-1 / 70 \mathrm{pg} \mathrm{mL}^{-1} \\
\text { in buffer } \\
1-5000 \mathrm{ng} \mathrm{mL}^{-1} / 210 \mathrm{pg} \mathrm{mL}^{-1} \\
\text { in reconstituted serum }\end{array}$ & $\mathrm{S}(1)$ & {$[63]$} \\
\hline CEA apt & $\mathrm{rG}+\mathrm{Strep}-\mathrm{CE} /$ direct & DPV of 2,3-diaminophenazine & $\begin{array}{c}5 \mathrm{pg} \mathrm{mL}^{-1}-50 \mathrm{ng} \mathrm{mL}^{-1} / \\
1.5 \mathrm{pg} \mathrm{mL}^{-1}\end{array}$ & S (8) & {$[64]$} \\
\hline $\begin{array}{l}\text { Capt: CEA apt 18-nt } \\
\text { Sign: CEA apt 19-nt }\end{array}$ & hemin-GO-GCE / sandwich & Electrochemiluminescence & $0.8-4 \mathrm{ng} \mathrm{mL}^{-1} / 0.28 \mathrm{pg} \mathrm{mL}^{-1}$ & S (9) & {$[65]$} \\
\hline CEA apt & $\begin{array}{c}\text { MB-aptamer-cDNA (capture) } \\
\text { NTH-cDNA2 on AuSPE (detection) } \\
\text { Strand displacement } \\
\end{array}$ & HCR+ DPV (hemin-G-quadruplex) & $\begin{array}{l}0.0001-50 \mathrm{ng} \mathrm{mL}^{-1} \\
\quad / 18.2 \mathrm{fg} \mathrm{mL}^{-1-}\end{array}$ & $\mathrm{S}(5)$ & {$[66]$} \\
\hline CEA apt & $\begin{array}{l}\text { NG/THI/PB-AuNPs/ GCE on paper/ } \\
\text { direct (signal off) }\end{array}$ & DPV of THI & $0.01-500 \mathrm{ng} \mathrm{mL}^{-1} / 2 \mathrm{pg} \mathrm{mL}^{-1}$ & $\mathrm{~S}(15)$ & {$[67]$} \\
\hline CEA apt & $\begin{array}{l}\text { rGO on p-nitrophenyl modified GCE } \\
\text { / homogeneous }\end{array}$ & $\begin{array}{l}\text { DPV of adsorbed MB-ssDNA after } \\
\text { exonuclease recycling }\end{array}$ & 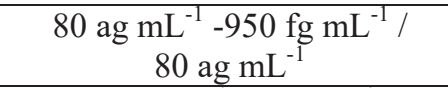 & $\mathrm{S}(5)$ & {$[68]$} \\
\hline Capt: anti-CEA Ab & GO-chitosan GCE / sandwich & RCA amplification + SWV of & $0.5 \mathrm{pg} \mathrm{mL}^{-1}-1 \mathrm{ng} \mathrm{mL}^{-1} /$ & $\mathrm{S}(7)$ & {$[69]$} \\
\hline
\end{tabular}




\begin{tabular}{|c|c|c|c|c|c|}
\hline Sign: CEA apt & & phosphomolybdate & $0.1 \mathrm{pg} \mathrm{mL}^{-1}$ & & \\
\hline $\begin{array}{l}\text { Capt \& sign: trimeric HER2- } \\
\text { neu apt or } \mathrm{Ab}\end{array}$ & $\begin{array}{c}\text { Strep-MB / sandwich with cellulose } \\
\text { labels }\end{array}$ & $\begin{array}{c}\text { Chronocoulometry (nitrocellulose enzymatic } \\
\text { degradation) }\end{array}$ & $10^{-15}-10^{-10} / 1 \mathrm{fM}^{* * *}$ & $\mathrm{~S} * * *$ & {$[70]$} \\
\hline $\begin{array}{c}\text { Capt: peptide } \\
\text { Sign: monomeric HER2 apt }\end{array}$ & $\mathrm{AuE} /$ sandwich & $\begin{array}{c}\text { HCR amplification + SWV of } \\
\text { phosphomolybdate }\end{array}$ & $1-100 \mathrm{pg} \mathrm{mL}^{-1} / 0.047 \mathrm{pg} \mathrm{mL}^{-1}$ & S (6) & [71] \\
\hline $\begin{array}{l}\text { Capt: CA125 Ab } \\
\text { Sign: CA125 apt }\end{array}$ & GO-chitosan GCE / sandwich & $\begin{array}{l}\text { HCR on AuNPs + SWV of } \\
\text { phosphomolybdate }\end{array}$ & $\begin{array}{c}100 \mu \mathrm{U} \mathrm{mL}^{-1}-10 \mathrm{U} \mathrm{mL}^{-1} / \\
50 \mu \mathrm{UL}^{-1}\end{array}$ & S (8) & {$[72]$} \\
\hline CA125 apt & $\begin{array}{c}\text { AgNPs amidoxime-modified } \\
\text { nanofibers on ITO/ strand } \\
\text { displacement }\end{array}$ & DPV of Methylene blue & $\begin{array}{c}0.01-350 \mathrm{U} \mathrm{mL}^{-1} / \\
0.0042 \mathrm{U} \mathrm{mL}^{-1}\end{array}$ & S (5) & {$[73]$} \\
\hline CA125 apt & rGO and MWCNT /direct (signal off) & Field effect transistor & $\begin{array}{l}10^{-9} \mathrm{U} \mathrm{mL}^{-1}-1 \mathrm{U} \mathrm{mL}^{-1} / \\
5 \times 10^{-10} \mathrm{U} \mathrm{mL}^{-1}\end{array}$ & S (1) & {$[74]$} \\
\hline $\begin{array}{l}\text { MUC1 apt hybridized to } \\
\text { cDNA }\end{array}$ & AuE / displacement assay & $\begin{array}{c}\text { DPV of metal ion labels and } \mathrm{Ru}\left(\mathrm{NH}_{3}\right)_{6}{ }^{3+} \\
\text { wires }\end{array}$ & $0.01 \mathrm{pM}-100 \mathrm{nM} / 3.33 \mathrm{fM}$ & S (5) & {$[62]$} \\
\hline NSE apt & $\begin{array}{l}\text { graphene/THI/PB-AuNPs-CE on } \\
\text { paper/ direct (signal off) }\end{array}$ & DPV of PB & $\begin{array}{c}0.05-500 \mathrm{ng} \mathrm{mL}^{-1} / \\
10 \mathrm{pg} \mathrm{mL}^{-1}\end{array}$ & $\mathrm{~S}(15)$ & {$[67]$} \\
\hline Osteopontin apt & Strep on AuSPE / direct (signal off) & $\mathrm{CV}$ and SWV of ferri/ferrocyanide & $\begin{array}{l}\text { CV: } 25-100 \mathrm{nM} / 2.6 \mathrm{nM}_{-} \text {in } \\
\text { buffer } \\
\text { SWV: } 12-100 \mathrm{nM} / 1.4 \mathrm{nM}_{-} \text {in } \\
\text { buffer; } 1.3 \mathrm{nM} \text { in serum }\end{array}$ & $\mathrm{S}(1)$ & {$[75]$} \\
\hline VEGF $_{165}$ apt & $\begin{array}{c}\text { BSA-Au nanoclusters on IL-GCE / } \\
\text { direct (signal off) }\end{array}$ & $\begin{array}{c}\text { EIS (ferri/ferrocyanide) signal on } \\
\text { DPV (methylene blue) }\end{array}$ & $\begin{array}{c}2.5-250 \mathrm{pM} / 0.48 \mathrm{pM} \\
1-120 \mathrm{pM} / 0.32 \mathrm{pM}\end{array}$ & S (3) & {$[76]$} \\
\hline VEGF $_{165}$ apt & OMC-Au composite-SPE / direct & EIS (ferri/ferrocyanide) & $10-300 \mathrm{pg} \mathrm{mL}^{-1} / 1 \mathrm{pg} \mathrm{mL}^{-1}$ & $\mathrm{~S}(1)$ & {$[77]$} \\
\hline Capt \& sign: PDGF-BB apt & AuNPs-rG-apt / sandwich & AuNP carrying apt and GOD + luminol ECL & $0.1 \mathrm{pM}-0.5 \mathrm{nM} / 17.4 \mathrm{fM}$ & $\mathrm{U}(3)$ & {$[52]$} \\
\hline PDGF-BB apt & $\mathrm{VS}_{2} / \mathrm{AuNP}-\mathrm{GCE} / \mathrm{direct}$ (signal off) & DPV of ferri/ferrocyanide & $1 \mathrm{pM}-1 \mathrm{nM} / 0.4 \mathrm{pM}$ & $\mathrm{U}(5)$ & [53] \\
\hline $\begin{array}{l}\text { Capt: EGFR apt } \\
\text { Sign: EGFR pAb }\end{array}$ & $\begin{array}{c}\text { Strept-MB with apt (capt) + AuNPs- } \\
\text { Ab (detection) }\end{array}$ & DPV of Au after acid dissolution & $1-40 \mathrm{ng} \mathrm{mL}^{-1} * / 50 \mathrm{pg} \mathrm{mL}^{-1}$ & $\mathrm{~S}(9)$ & {$[78]$} \\
\hline IL-6 apt & Graphene / direct (signal off) & Field effect transistor & $\begin{array}{c}0.05-20 \mathrm{nM}^{* *} / \\
10.5 \mathrm{pM} \text { in PBS } \\
11.8 \mathrm{pM} \text { in artificial gargle } \\
12.2 \mathrm{pM} \text { in human saliva }\end{array}$ & SL (3) & {$[54]$} \\
\hline $\begin{array}{l}\text { Apt for unknown lung cancer } \\
\text { proteins }\end{array}$ & AuSPE / direct (signal off) & SWV of ferri/ferrocyanide & $\begin{array}{l}0.023-230 \mathrm{ng} \mathrm{mL}^{-1} / \\
0.023 \mathrm{ng} \mathrm{mL}^{-1}\end{array}$ & $\mathrm{P}(13)$ & [42] \\
\hline
\end{tabular}

*Two linear ranges $* *$ Non-linear calibration $* * *$ only tested with antibodies 
Apt: aptamer; AuE: gold electrode; BSA: bovine serum albumin; Cap: capture; cDNA: complementary DNA; CE: carbon electrode; DPV: differential pulse voltammetry, ECL: electrochemiluminescence; EIS: electrochemical impedance spectroscopy; GCE: glassy carbon electrode; GOD: glucose oxidase, IL: ionic liquid; MWCNT: multi-walled carbon nanotubes; NTH: nanotetraedron; OMC: ordered mesoporous carbon; P: plasma; PB: prussian blue; rG: reduced graphene; S: serum; Sign: signaling; SL: saliva; SPE: screen printed electrode; SWV: square wave voltammetry; Strep: streptavidin; THI: thionine; U:urine

Table 2: Summary of analytical characteristics of published electrochemical aptamer-based assays for CTCs detection

\begin{tabular}{|c|c|c|c|c|c|}
\hline Receptor & Sensing platform / Assay format & Detection method & $\begin{array}{l}\text { Linear Range \& } \\
\text { LOD (cells mL } \mathrm{mL}^{-1} \text { ) }\end{array}$ & Sample (number) & Ref. \\
\hline EpCAM apt & $\begin{array}{l}\text { AuE-cDNA partially hybridized } \\
\text { with apt / Direct }\end{array}$ & EIS & $\begin{array}{c}30 \times 10^{6} / \\
10\end{array}$ & $\begin{array}{c}\text { MCF-7 } \\
\text { Spiked serum }\end{array}$ & {$[98]$} \\
\hline $\begin{array}{l}\text { Cap: EpCAM Ab } \\
\text { Sign: EpCAM aptr }\end{array}$ & $\begin{array}{c}\text { MB (capt) }+ \text { AuE electrode } \\
\text { (detection) } / \\
\text { Sandwich } \\
\end{array}$ & $\begin{array}{c}\text { RCA + SWV of } \\
\text { phosphomolybdate }\end{array}$ & $5-30000 / 1$ & $\begin{array}{l}\text { MCF-7 (breast cancer) } \\
\text { Spiked whole blood }\end{array}$ & [99] \\
\hline $\begin{array}{l}\text { Cap: EpCAM apt } \\
\text { Sign: Concavalin A }\end{array}$ & $\begin{array}{c}\mathrm{Fe}_{3} \mathrm{O}_{4} @ \mathrm{SiO}_{2}-\mathrm{NH}_{2}-\mathrm{NPs} \text { (capture) }+ \\
\mathrm{AuE} \text { (detection) } \\
\text { Sandwich }\end{array}$ & $\begin{array}{l}\text { Pd@AuNPs catalysis } \\
\text { Chronoamperometry }\end{array}$ & $100-1 \times 10^{6} / 30$ & MCF-7 & {$[100]$} \\
\hline $\begin{array}{l}\text { Cap: MUC1 apt } \\
\text { Sign: MUC1 apt }\end{array}$ & $\begin{array}{l}\text { GCE-rGO-AuNPs } \\
\text { Sandwich } \\
\end{array}$ & DPV (CuO nanozyme) & $50-7 \times 10^{3} / 27$ & $\begin{array}{c}\text { MCF-7 } \\
\text { Spiked artificial human serum }\end{array}$ & {$[101]$} \\
\hline $\begin{array}{l}\text { AS1411 \& MUC1 apt (both for } \\
\text { Cap and Sign) }\end{array}$ & $\begin{array}{l}\text { Au-NTH-bearing aptamers } \\
\text { Sandwich }\end{array}$ & $\begin{array}{l}\text { MOF-PtNPs decorated with } \\
\text { apt and DNAzyme- DPV }\end{array}$ & $\begin{array}{c}20-1 \times 10^{7} \\
6\end{array}$ & $\begin{array}{c}\text { MCF-7 } \\
\text { Spiked in blood }\end{array}$ & {$[102]$} \\
\hline PTK7 apt & $\begin{array}{l}\text { GCE-Au nanostars } \\
\text { Direct (signal off) }\end{array}$ & DPEE with AA & $5-1 \times 10^{5} / 5$ & $\begin{array}{c}\text { CCRF-CEM } \\
\text { Spiked in } 10 \% \text { human serum }\end{array}$ & {$[105]$} \\
\hline Cap: PTK7 apt & $\begin{array}{l}\text { AuNP-apt (capture) } \\
\text { AuE-hairpin probe / strand } \\
\text { displacement ( signal off) }\end{array}$ & $\begin{array}{c}\text { NEase-TCEP } \\
\text { SWV of methylene blue }\end{array}$ & $5-5000 / 1$ & $\begin{array}{c}\text { CCRF-CEM } \\
\text { Spiked in blood samples }\end{array}$ & {$[106]$} \\
\hline Cap: PTK7 apt & $\begin{array}{l}\text { Array nanochannel-ion channel } \\
\text { hybrid (silanized PAA } \\
\text { membrane- } \mathrm{NH}_{2} \text {-aptamer) /direct }\end{array}$ & $\begin{array}{c}\text { LSV } \\
\text { (blockage of ionic flow } \\
\text { through channels) }\end{array}$ & $\begin{array}{c}100-1000 / \\
100\end{array}$ & CCRF-CEM & {$[107]$} \\
\hline $\begin{array}{l}\text { Cap \& Sign of Ramos: } \\
\text { Ig heavy Mu chain apt }\end{array}$ & $\begin{array}{l}\text { Magnetic nanocomposite (capt) }+ \\
\text { CE (detection) }\end{array}$ & $\begin{array}{l}\text { SWV Fc and THI attached to } \\
\text { AuNPs }\end{array}$ & $\begin{array}{c}5-500 \text { (both) } \\
4 \text { (Ramos) and } 3\end{array}$ & $\begin{array}{l}\text { Ramos \& CCRF-CEM } \\
\text { Spiked whole blood }\end{array}$ & {$[108]$} \\
\hline
\end{tabular}




\begin{tabular}{|c|c|c|c|c|c|}
\hline $\begin{array}{c}\text { Cap \& Sign of CCRF-CEM: } \\
\text { PTK7 apt }\end{array}$ & Sandwich & & (CCRF-CEM) & Blood from leukemia patients (3) & \\
\hline $\begin{array}{l}\text { Hepatocellular carcinoma- } \\
\text { specific apt }\end{array}$ & $\begin{array}{c}\text { Au-NTH +aptamer-PtNPs-primer } \\
\text { RCA / Strand displacement }\end{array}$ & $\begin{array}{c}\text { DPV of HRP-mimicking } \\
\text { DNAzyme generated by RCA }\end{array}$ & $\begin{array}{c}10-1 \times 10^{6} / \\
3\end{array}$ & $\begin{array}{c}\text { HepG2 } \\
\text { Spiked in blood }\end{array}$ & {$[110]$} \\
\hline Cap: two types of MEAR apt & GCE / Direct (signal off) & DPV of ferri/ferrocyanide & $1-14 / 1$ & $\begin{array}{c}\text { MEAR } \\
\text { Spiked in blood }\end{array}$ & {$[111]$} \\
\hline AS1411 apt & $\begin{array}{c}\mathrm{Si}_{3} \mathrm{~N}_{4} \text {-APTES-GO-CO } \mathrm{CO}_{2} \mathrm{H} \\
\text { Direct (signal off) }\end{array}$ & LAPS & $\begin{array}{c}5 \times 10^{3}-5 \times 10^{6} / \\
5 \times 10^{3}\end{array}$ & $\begin{array}{c}\text { HeLa, A549, MB231 } \\
\text { Spiked in blood } \\
\text { Blood breast cancer patients (8) }\end{array}$ & {$[112]$} \\
\hline
\end{tabular}

AA: ascorbic acid; DPEE: direct plasmon-enhanced electrochemistry; Fc: Ferrocene; HRP: horseradish peroxidase; LAPS: Light addressable potentiometric sensor; LSV: linear sweep voltammetry; MOF: metal organic framework; NEase: nicking endonuclease; PAA: porous anodic alumina; (r)GO: (reduced) graphene oxide; TCEP: Trigged cascade displacement polymerization;

Table 3: Summary of analytical characteristics of published electrochemical aptamer-based assays for exosome detection

\begin{tabular}{|c|c|c|c|c|c|}
\hline Receptor & Sensing platform / Assay format & Detection method & $\begin{array}{c}\text { Linear Range / LOD } \\
\left(\text { part. } \mathrm{mL}^{-1}\right)\end{array}$ & Sample (number) & Ref. \\
\hline $\begin{array}{l}\text { Cap: EpCAM apt } \\
\text { Sign: CD63 apt }\end{array}$ & $\begin{array}{l}\text { AuNPs/GCE } \\
\text { Sandwich }\end{array}$ & $\begin{array}{l}\text { ECL of luminol catalyze by } \mathrm{Ti}_{3} \mathrm{C}_{2} \\
\text { MXenes }\end{array}$ & $\begin{array}{c}5 \times 10^{5}-5 \times 10^{9} \\
1.25 \times 10^{4}\end{array}$ & $\begin{array}{c}\text { MCF-7 } \\
\text { Spiked serum }\end{array}$ & {$[118]$} \\
\hline $\begin{array}{c}\text { Cap: CD63 apt } \\
\text { Sign: EpCAM apt }\end{array}$ & $\begin{array}{c}\mathrm{MB}(\text { capt })+\text { Au electrode (detection) } \\
\text { Sandwich }\end{array}$ & $\begin{array}{l}\text { DNAzyme-exonuclease activity- DNA } \\
\text { release DPV of MB and Fc (ratiometric) }\end{array}$ & $\begin{array}{c}5 \times 10^{4}-1 \times 10^{10} \\
1.2 \times 10^{4}\end{array}$ & $\begin{array}{c}\text { MCF-7 } \\
\text { Serum from breast cancer } \\
\text { patients }(3)\end{array}$ & [119] \\
\hline CD63 apt & $\begin{array}{l}\text { Homogeneous, Direct } \\
\text { ITO electrode }\end{array}$ & $\begin{array}{l}\text { DNA release- ExoIII assisted recycling } \\
\text { DPV Doxorubicin }\end{array}$ & $\begin{array}{c}3.4 \times 10^{4}-3.4 \times 10^{8} \\
1.2 \times 10^{4}\end{array}$ & $\begin{array}{c}\text { MCF-7 } \\
\text { Spiked serum }\end{array}$ & {$[120]$} \\
\hline CD63 apt & $\begin{array}{c}\text { Au-rGO-GCE } \\
\text { Direct- labelled exosomes }\end{array}$ & $\begin{array}{l}\text { DNA linked to exosomes } \\
\text { Hybridization chain reaction } \\
\text { Streptavidin-HRP- DPV }\end{array}$ & $\begin{array}{c}1.2 \times 10^{5}-1.2 \times 10^{11} \\
9.6 \times 10^{4}\end{array}$ & $\begin{array}{c}\text { MCF-7 } \\
\text { Serum from breast cancer } \\
\text { patients }(1)\end{array}$ & {$[121]$} \\
\hline $\begin{array}{l}\text { Cap: CD63 apt } \\
\text { Sign: CD63 apt- } \\
\text { DNAzyme }\end{array}$ & $\begin{array}{l}\text { GCE-CdS:Eu nanocrystals } \\
\text { Sandwich (Signal-off) }\end{array}$ & DNAzyme/hemin ECL & $\begin{array}{c}3.4 \times 10^{5}-1.7 \times 10^{8} \\
7.4 \times 10^{4}\end{array}$ & $\begin{array}{c}\text { MCF-7 } \\
\text { Serum from breast cancer } \\
\text { patients }(8)\end{array}$ & {$[122]$} \\
\hline $\begin{array}{l}\text { Cap: CD63 Ab } \\
\text { Sign: CD63 apt }\end{array}$ & $\begin{array}{c}\text { MB (capture) }+ \text { AuE (detection) } \\
\text { Sandwich }\end{array}$ & $\begin{array}{l}\text { Cascade toehold mediated strand } \\
\text { displacement- MB duplex, SWV }\end{array}$ & $\begin{array}{c}1 \times 10^{5}-5 \times 10^{7} \\
1.7 \times 10^{4}\end{array}$ & $\begin{array}{c}\text { HepG2 } \\
\text { Spiked serum }\end{array}$ & {$[123]$} \\
\hline
\end{tabular}




\begin{tabular}{|c|c|c|c|c|c|}
\hline $\begin{array}{c}\text { Cap: Tim4 } \\
\text { Sign: CD63 apt }\end{array}$ & $\begin{array}{c}\text { MB (capture) + ITO (detection) } \\
\text { Sandwich }\end{array}$ & $\begin{array}{c}\text { DNAzyme-aptamer } \\
\text { Hemin for peroxidase activity } \\
\text { DPV of thionine }\end{array}$ & $\begin{array}{c}7.6 \times 10^{4}-7.6 \times 10^{8} \\
4.4 \times 10^{3}\end{array}$ & $\begin{array}{c}\text { HepG2 } \\
\begin{array}{c}\text { Serum from liver cancer } \\
\text { patients }(10)\end{array}\end{array}$ & [124] \\
\hline CD63 aptr & $\begin{array}{l}\text { AuE Direct- displacement of MB- } \\
\text { DNA (signal-off) }\end{array}$ & DPV of MB & $\begin{array}{c}1 \times 10^{6}-1 \times 10^{8} \\
1 \times 10^{6}\end{array}$ & $\begin{array}{c}\text { HepG2 } \\
\text { Spiked serum }\end{array}$ & {$[125]$} \\
\hline $\begin{array}{l}\text { Cap: EpCAM apt } \\
\text { Sign1: EpCAM apt } \\
\text { Sign2: PSMA apt }\end{array}$ & $\begin{array}{l}\text { Nanostructured AuE } \\
\text { Sandwich }\end{array}$ & CuNP and AgNP electrooxidation- LSV & $\begin{array}{l}\text { Not provided } \\
2 \times 10^{3}\end{array}$ & $\begin{array}{c}\text { VCap } \\
\text { Serum from prostate cancer } \\
\text { patients }(10)\end{array}$ & [127] \\
\hline $\begin{array}{l}\text { Cap: CD63 Ab } \\
\text { Sign: MUC1 apt }\end{array}$ & $\begin{array}{c}\text { AuE / } \\
\text { Sandwich }\end{array}$ & $\begin{array}{c}\text { RCA - hemin/DNAzyme reporter } \\
\text { DPV }\end{array}$ & $\begin{array}{c}4.8 \times 10^{3}-4.8 \times 10^{6} \\
9.5 \times 10^{2}\end{array}$ & $\begin{array}{c}\text { SGC7901 } \\
\text { Serum from gastric cancer } \\
\text { patients }(16)\end{array}$ & {$[128]$} \\
\hline PSMA apt & $\begin{array}{c}\text { MB (capture) Direct, displacement } \\
\text { DNA }(\times 3)-\text { AuE (signal off) }\end{array}$ & $\begin{array}{l}\text { Exo III-assisted target recycling. DPV } \\
\qquad \mathrm{Ru}\left(\mathrm{NH}_{3}\right)_{6}{ }^{3+} \text { reporter } \\
\end{array}$ & $\begin{array}{c}1 \times 10^{3}-1.2 \times 10^{5} \\
7 \times 10^{4}\end{array}$ & $\begin{array}{c}\text { LNCap } \\
\text { Spiked serum }\end{array}$ & [129] \\
\hline LZH8 apt & AuE / Direct (signal off) & SWV Ferro/ferricyanide & $\begin{array}{c}1 \times 10^{5}-1 \times 10^{12} \\
2.1 \times 10^{4}\end{array}$ & HepG2 & [131] \\
\hline
\end{tabular}

Tim4: Phosphatidylserine binding-protein 


\section{Captions for figures}

Figure 1: Scheme of the SELEX procedure including the common iterative steps: interaction between the library and the target for cancer diagnosis (left wheel) that takes place in one of the milieu indicated in the right wheel; separation of bound from unbound sequences, elution of the bound sequences from the target to obtain a pool of strands with higher affinity, PCR amplification of enriched pool and conditioning to obtain single stranded DNA to start a new round of selection. Counter and negative steps are not included for clarity. When the enrichment is sufficient, the last step is the massive sequencing or alternatively cloning and sequencing of a limited number of strands.

Figure 2: Direct aptamer assays for the detection of protein tumor biomarkers. (A) Homogeneous "signal-on" assay based on two coupled nuclease-assisted recycling schemes, which renders a shortened methylene-blue reporter strand that adsorbs on the graphene oxide modified electrode. Adapted with permission from Ref. [68]. (B) Aptasensor using AuNPs to anchor the capture aptamer with two detection modes: "signal-off" voltammetric (upper scheme) and "signal-on" impedimetric measurements (bottom scheme). Adapted with permission from Ref. [76].

Figure 3: Sandwich assays for protein tumor biomarkers using aptamers as a reporting element. (A) Aptasensor for PSA with aptamer for capturing and chronoamperometric detection on disposable electrodes. Reprinted with permission from Ref. [61]. (B) Aptasensor for CA125 using an antibody for capturing and nanoparticles to assist the hybridization chain reaction enabling the amplification of the signal due to the soluble reporter molecule. Adapted with permission from Ref. [72].

Figure 4: Direct aptassays for CTCs detection. (A) "Signal-on" impedimetric cytosensor with subsequent enzyme-based cell recovery. Adapted with permission from Ref. [98]. (B) "Signal-off "cytoassays based on a nanochannel-ion channel hybrid. Adapted with permission from Ref. [107]. 
Figure 5: Sandwich aptaassays for CTCs detection. (A) Cytosensor based on a DNA walking strategy using AuNPs. Reprinted with permission from Ref. [106]. (B) Dual cytoassay based on nanostructures for capture and signal amplification. Reprinted with permission from Ref. [108]. (C) Voltammetric cytosensor based on nanoprobes carrying HRP-mimicking DNAzymes. Adapted with permission from Ref. [102]. (D) Voltammetric cytosensor based on $\mathrm{CuO}$ nanoparticles serving as nanoenzymes. Reprinted with permission from Ref. [101].

Figure 6: Aptasensor designs to detect exosomes. (A) Direct and "signal-off" aptasensor where the aptamer is immobilized through a DNA-nanotetrahedron. Reprinted with permission from Ref. [131]. (B) Displacement design: the recognition of exosomes by the aptamer displaces the hybridized reporter probe, with the subsequent decrease in the signal of the label, methylene blue (MB). Reprinted with permission from Ref. [125]. (C) Immobilized aptamers directly entrap exosomes, which are linked to a reporter probe by a click chemistry process. This probe is amplified in a hybridization chain reaction (HCR) using two biotin-hairpins (biotin-H1 and biotin-H2). The subsequent binding of streptavidin-HRP reports the recognition, after the addition of the substrate of peroxidase, in a "signal-on" response. Reprinted with permission from Ref. [121].

Figure 7: Signal generation and amplifications strategies in sandwich aptasensors to detect exosomes. (A) Dual sensor based on the electrooxidation of metal nanoparticles linked to the reporter aptamers. Reprinted with permission from Ref. [127]. (B) The aptamer is linked with a primer for RCA. After the RCA elongation, a G-quadruplex is formed, which in the presence of hemin is responsible for the voltammetric signal. Reprinted with permission from reference [128]. (C) The interaction between exosomes and the capture receptor (the binding protein Tim 4), immobilized onto magnetic beads, takes place in a microchamber of a microfluidic chip. The beads are magnetically driven to an ITO electrode, where the aptamer elongated with a DNAzyme sequence binds, generating the electrochemical signal in the presence of hemin. Reprinted with permission from reference [124]. 


\section{REFERENCES}

[1] S. Gilgunn, P.J. Conroy, R. Saldova, P.M. Rudd, R.J. O'Kennedy, Aberrant PSA glycosylation--a sweet predictor of prostate cancer, Nat Rev Urol, 10 (2013) 99-107.

[2] C. Tuerk, L. Gold, Systematic evolution of ligands by exponential enrichment RNA ligands to bacteriophage-T4 DNA-polymerase, Science, 249 (1990) 505-510.

[3] A.D. Ellington, J.W. Szostak, Invitro selection of RNA molecules that bind specific ligands, Nature, 346 (1990) 818-822.

[4] H. Kaur, J.G. Bruno, A. Kumar, T.K. Sharma, Aptamers in the therapeutics and diagnostics pipelines, Theranostics, 8 (2018) 4016-4032.

[5] D. Xiang, et al., Superior performance of aptamer in tumor penetration over antibody: Implication of aptamer-based theranostics in solid tumors, Theranostics, 5 (2015) 1083-1097.

[6] E.V. Suprun, Protein post-translational modifications - A challenge for bioelectrochemistry, TRAC Trends Anal Chem, 116 (2019) 44-60.

[7] A.A. Sina, et al., Epigenetically reprogrammed methylation landscape drives the DNA self-assembly and serves as a universal cancer biomarker, Nat Commun, 9 (2018) 4915.

[8] R. Aebersold, et al., How many human proteoforms are there?, Nat Chem Biol, 14 (2018) 206-214.

[9] M. Baker, Reproducibility crisis: Blame it on the antibodies, Nature, 521 (2015) 274-276.

[10] R. O'Kennedy, S. Fitzgerald, C. Murphy, Don't blame it all on antibodies - The need for exhaustive characterisation, appropriate handling, and addressing the issues that affect specificity, TRAC Trends Anal Chem, 89 (2017) 53-59.

[11] M. Uhlen, et al., A proposal for validation of antibodies, Nat Methods, 13 (2016) 823-827. 
[12] https://proteomics.cancer.gov/antibody-portal, December 26, 2019.

[13] T.K. Sharma, J.G. Bruno, A. Dhiman, ABCs of DNA aptamer and related assay development, Biotechnol Adv, 35 (2017) 275-301.

[14] T. Wang, C. Chen, L.M. Larcher, R.A. Barrero, R.N. Veedu, Three decades of nucleic acid aptamer technologies: Lessons learned, progress and opportunities on aptamer development, Biotechnol Adv, 37 (2019) 28-50.

[15] C. Zong, J. Liu, The arsenic-binding aptamer cannot bind arsenic: Critical evaluation of aptamer selection and binding, Anal Chem, 91 (2019) 10887-10893.

[16] I. Alvarez-Martos, E.E. Ferapontova, A DNA sequence obtained by replacement of the dopamine RNA aptamer bases is not an aptamer, Biochem Biophys Res Commun, 489 (2017) 381-385.

[17] R. Lorenzo-Gómez, N. Fernández-Alonso, R. Miranda-Castro, N. de-los-SantosÁlvarez, M.J. Lobo-Castañón, Unravelling the lipocalin 2 interaction with aptamers: May rolling circle amplification improve their functional affinity?, Talanta, 197 (2019) 406-412.

[18] K. Ikebukuro, C. Kiyohara, K. Sode, Electrochemical detection of protein using a double aptamer sandwich, Anal Lett, 37 (2004) 2901-2909.

[19] H. Sun, W. Tan, Y. Zu, Aptamers: versatile molecular recognition probes for cancer detection, Analyst, 141 (2016) 403-415.

[20] H. Safarpour, S. Dehghani, R. Nosrati, N. Zebardast, M. Alibolandi, A. Mokhtarzadeh, M. Ramezani, Optical and electrochemical-based nano-aptasensing approaches for the detection of circulating tumor cells (CTCs), Biosens Bioelectron, 148 (2020) 111833.

[21] W. Zhou, P.-J. Jimmy Huang, J. Ding, J. Liu, Aptamer-based biosensors for biomedical diagnostics, Analyst, 139 (2014) 2627-2640.

[22] M. Jarczewska, Ł. Górski, E. Malinowska, Electrochemical aptamer-based biosensors as potential tools for clinical diagnostics, Anal Methods, 8 (2016) 38613877. 
[23] M. Hasanzadeh, N. Shadjou, M. de la Guardia, Aptamer-based assay of biomolecules: Recent advances in electro-analytical approach, TRAC Trends Anal Chem, 89 (2017) 119-132.

[24] D. Sadighbayan, K. Sadighbayan, M.R. Tohid-kia, A.Y. Khosroushahi, M. Hasanzadeh, Development of electrochemical biosensors for tumor marker determination towards cancer diagnosis: Recent progress, TRAC Trends Anal Chem, 118 (2019) 73-88.

[25] S.N. Topkaya, M. Azimzadeh, M. Ozsoz, Electrochemical biosensors for cancer biomarkers detection: Recent advances and challenges, Electroanalysis, 28 (2016) 14021419.

[26] S. Dehghani, et al., Aptamer-based biosensors and nanosensors for the detection of vascular endothelial growth factor (VEGF): A review, Biosens Bioelectron, 110 (2018) 23-37.

[27] M. Yousefi, et al., Aptasensors as a new sensing technology developed for the detection of MUC1 mucin: A review, Biosens Bioelectron, 130 (2019) 1-19.

[28] P. Jolly, N. Formisano, P. Estrela, DNA aptamer-based detection of prostate cancer, Chemical Papers, 69 (2015) 77-89.

[29] D. Sun, J. Lu, L. Zhang, Z. Chen, Aptamer-based electrochemical cytosensors for tumor cell detection in cancer diagnosis: A review, Anal Chim Acta, 1082 (2019) 1-17.

[30] R. Eivazzadeh-Keihan, P. Pashazadeh-Panahi, B. Baradaran, A. Maleki, M. Hejazi, A. Mokhtarzadeh, M. de la Guardia, Recent advances on nanomaterial based electrochemical and optical aptasensors for detection of cancer biomarkers, TRAC Trends Anal Chem, 100 (2018) 103-115.

[31] Y. Yang, X. Yang, Y. Yang, Q. Yuan, Aptamer-functionalized carbon nanomaterials electrochemical sensors for detecting cancer relevant biomolecules, Carbon, 129 (2018) 380-395. 
[32] E.M. Hassan, M.C. DeRosa, Recent advances in cancer early detection and diagnosis: Role of nucleic acid based aptasensors, TRAC Trends Anal Chem, 124 (2020) 115806.

[33] R. Miranda-Castro, I. Palchetti, N. de-los-Santos-Álvarez, The Translational Potential of Electrochemical DNA-Based Liquid Biopsy, Frontiers in Chemistry, 8 (2020).

[34] E.J. Cho, J.W. Lee, A.D. Ellington, Applications of aptamers as sensors, Annu Rev Anal Chem, 2 (2009) 241-264.

[35] Z. Tang, et al., Selection of aptamers for molecular recognition and characterization of cancer cells, Anal Chem, 79 (2007) 4900-4907.

[36] S. Goto, K. Tsukakoshi, K. Ikebukuro, Development of aptamers against unpurified proteins, Biotechnol Bioeng, 114 (2017) 2706-2716.

[37] Y. Zheng, et al., DNA aptamers from whole-serum SELEX as new diagnostic agents against gastric cancer, RSC Advances, 9 (2019) 950-957.

[38] K. Li, L. Qi, L. Gao, M. Shi, J. Li, Z. Liu, L. Zhao, Selection and preliminary application of a single stranded DNA aptamer targeting colorectal cancer serum, RSC Advances, 9 (2019) 38867-38876.

[39] T. Wang, W.-X. Chen, G.-F. Xu, B. Zhang, S.-Q. Wei, J. Hu, K.-H. Zhang, A universal strategy designed for selecting bench-to-bedside aptamers to serum and validated in hepatocellular carcinoma diagnosis, Microchem J, 150 (2019) 104152.

[40] J.G. Bruno, Effects of various additives on cancer biomarker aptamer-magnetic pull-down in human serum, J Bionanosci, 11 (2017) 45-51.

[41] G.S. Zamay, et al., Aptamers selected to postoperative lung adenocarcinoma detect circulating tumor cells in human blood, Mol Ther, 23 (2015) 1486-1496.

[42] G.S. Zamay, et al., Electrochemical aptasensor for lung cancer-related protein detection in crude blood plasma samples, Sci Rep, 6 (2016) 34350. 
[43] S. Li, et al., Identification of an aptamer targeting hnRNP A1 by tissue slide-based SELEX, J Pathol, 218 (2009) 327-336.

[44] H. Wang, et al., Morph-X-Select: Morphology-based tissue aptamer selection for ovarian cancer biomarker discovery, BioTechniques, 61 (2016) 249-259.

[45] W.-T. Liu, W.-B. Lee, Y.-C. Tsai, Y.-J. Chuang, K.-F. Hsu, G.-B. Lee, An automated microfluidic system for selection of aptamer probes against ovarian cancer tissues, Biomicrofluidics, 13 (2019) 014114.

[46] W. Zhong, et al., Identification and application of an aptamer targeting papillary thyroid carcinoma using tissue-SELEX, Anal Chem, 91 (2019) 8289-8297.

[47] J. Mi, Y. Liu, Z.N. Rabbani, Z. Yang, J.H. Urban, B.A. Sullenger, B.M. Clary, In vivo selection of tumor-targeting RNA motifs, Nat Chem Biol, 6 (2010) 22-24.

[48] J. Mi, et al., In vivo selection against human colorectal cancer xenografts identifies an aptamer that targets RNA helicase protein DHX9, Mol Ther Nucleic Acids, 5 (2016) e315.

[49] H. Wang, Y. Zhang, H. Yang, M. Qin, X. Ding, R. Liu, Y. Jiang, In vivo SELEX of an inhibitory NSCLC-specific RNA aptamer from PEGylated RNA library, Mol Ther Nucleic Acids, 10 (2018) 187-198.

[50] L. Civit, et al., Targeting hormone refractory prostate cancer by in vivo selected DNA libraries in an orthotopic xenograft mouse model, Sci Rep, 9 (2019) 4976.

[51] L. Chen, et al., In vivo SELEX of bone targeting aptamer in prostate cancer bone metastasis model, Int J Nanomedicine, 14 (2018) 149-159.

[52] J.-J. Zhang, J.-T. Cao, G.-F. Shi, K.-J. Huang, Y.-M. Liu, S.-W. Ren, A luminol electrochemiluminescence aptasensor based on glucose oxidase modified gold nanoparticles for measurement of platelet-derived growth factor BB, Talanta, 132 (2015) 65-71.

[53] X. Liu, H.-L. Shuai, K.-J. Huang, A label-free electrochemical aptasensor based on leaf-like vanadium disulfide-Au nanoparticles for the sensitive and selective detection of platelet-derived growth factor BB, Anal Methods, 7 (2015) 8277-8284. 
[54] Z. Hao, Y. Pan, W. Shao, Q. Lin, X. Zhao, Graphene-based fully integrated portable nanosensing system for on-line detection of cytokine biomarkers in saliva, Biosens Bioelectron, 134 (2019) 16-23.

[55] M. Heiat, M. Negahdary, Sensitive diagnosis of alpha-fetoprotein by a label free nanoaptasensor designed by modified $\mathrm{Au}$ electrode with spindle-shaped gold nanostructure, Microchem J, 148 (2019) 456-466.

[56] M. Cui, Y. Wang, M. Jiao, S. Jayachandran, Y. Wu, X. Fan, X. Luo, Mixed selfassembled aptamer and newly designed zwitterionic peptide as antifouling biosensing interface for electrochemical detection of alpha-fetoprotein, ACS Sens, 2 (2017) 490494.

[57] A. Rahi, N. Sattarahmady, H. Heli, Label-free electrochemical aptasensing of the human prostate-specific antigen using gold nanospears, Talanta, 156-157 (2016) 218224.

[58] E. Heydari-Bafrooei, N.S. Shamszadeh, Electrochemical bioassay development for ultrasensitive aptasensing of prostate specific antigen, Biosens Bioelectron, 91 (2017) 284-292.

[59] B. Wei, K. Mao, N. Liu, M. Zhang, Z. Yang, Graphene nanocomposites modified electrochemical aptamer sensor for rapid and highly sensitive detection of prostate specific antigen, Biosens Bioelectron, 121 (2018) 41-46.

[60] N. Sattarahmady, A. Rahi, H. Heli, A signal-on built in-marker electrochemical aptasensor for human prostate-specific antigen based on a hairbrush-like gold nanostructure, Sci Rep, 7 (2017) 11238.

[61] A. Díaz-Fernández, R. Miranda-Castro, N. de-los-Santos-Álvarez, E.F. Rodríguez, M.J. Lobo-Castañón, Focusing aptamer selection on the glycan structure of prostatespecific antigen: Toward more specific detection of prostate cancer, Biosens Bioelectron, 128 (2019) 83-90.

[62] C. Ma, H. Liu, L. Zhang, H. Li, M. Yan, X. Song, J. Yu, Multiplexed aptasensor for simultaneous detection of carcinoembryonic antigen and mucin-1 based on metal ion 
electrochemical labels and $\mathrm{Ru}\left(\mathrm{NH}_{3}\right)_{6}{ }^{3+}$ electronic wires, Biosens Bioelectron, 99 (2018) $8-13$.

[63] G. Paniagua, et al., Amperometric aptasensor for carcinoembryonic antigen based on the use of bifunctionalized Janus nanoparticles as biorecognition-signaling element, Anal Chim Acta, 1061 (2019) 84-91.

[64] W. Wen, et al., Increased electrocatalyzed performance through hairpin oligonucleotide aptamer-functionalized gold nanorods labels and graphene-streptavidin nanomatrix: Highly selective and sensitive electrochemical biosensor of carcinoembryonic antigen, Biosens Bioelectron, 83 (2016) 142-148.

[65] J.-J. Yang, J.-T. Cao, Y.-L. Wang, H. Wang, Y.-M. Liu, S.-H. Ma, Sandwich-like electrochemiluminescence aptasensor based on dual quenching effect from hemingraphene nanosheet and enzymatic biocatalytic precipitation for sensitive detection of carcinoembryonic antigen, J Electroanal Chem, 787 (2017) 88-94.

[66] Z. Liu, S. Lei, L. Zou, G. Li, L. Xu, B. Ye, A label-free and double recognitionamplification novel strategy for sensitive and accurate carcinoembryonic antigen assay, Biosens Bioelectron, 131 (2019) 113-118.

[67] Y. Wang, et al., Label-free microfluidic paper-based electrochemical aptasensor for ultrasensitive and simultaneous multiplexed detection of cancer biomarkers, Biosens Bioelectron, 136 (2019) 84-90.

[68] L. Ge, W. Wang, X. Sun, T. Hou, F. Li, Affinity-mediated homogeneous electrochemical aptasensor on a graphene platform for ultrasensitive biomolecule detection via exonuclease-assisted target-analog recycling amplification, Anal Chem, 88 (2016) 2212-2219.

[69] W. Jiang, L. Liu, L. Zhang, Q. Guo, Y. Cui, M. Yang, Sensitive immunosensing of the carcinoembryonic antigen utilizing aptamer-based in-situ formation of a redoxactive heteropolyacid and rolling circle amplification, Microchim Acta, 184 (2017) 4757-4763. 
[70] K. Malecka, D. Pankratov, E.E. Ferapontova, Femtomolar electroanalysis of a breast cancer biomarker HER-2/neu protein in human serum by the cellulase-linked sandwich assay on magnetic beads, Anal Chim Acta, 1077 (2019) 140-149.

[71] C. Shen, K. Zeng, J. Luo, X. Li, M. Yang, A. Rasooly, Self-assembled DNA generated electric current biosensor for HER2 analysis, Anal Chem, 89 (2017) 1026410269.

[72] Y. Nie, M. Yang, Y. Ding, Gold nanoparticle enhanced hybridization chain reaction as a method for signal amplification. Application to electrochemical immunodetection of the ovarian cancer biomarker carbohydrate antigen 125, Microchim Acta, 185 (2018) 331.

[73] L. Farzin, S. Sadjadi, M. Shamsipur, S. Sheibani, M.h. Mousazadeh, Employing AgNPs doped amidoxime-modified polyacrylonitrile (PAN-oxime) nanofibers for target induced strand displacement-based electrochemical aptasensing of CA125 in ovarian cancer patients, Mater Sci Eng C, 97 (2019) 679-687.

[74] S. Mansouri Majd, A. Salimi, Ultrasensitive flexible FET-type aptasensor for CA 125 cancer marker detection based on carboxylated multiwalled carbon nanotubes immobilized onto reduced graphene oxide film, Anal Chim Acta, 1000 (2018) 273-282.

[75] S.G. Meirinho, L.G. Dias, A.M. Peres, L.R. Rodrigues, Electrochemical aptasensor for human osteopontin detection using a DNA aptamer selected by SELEX, Anal Chim Acta, 987 (2017) 25-37.

[76] M. Shamsipur, L. Farzin, M. Amouzadeh Tabrizi, F. Molaabasi, Highly sensitive label free electrochemical detection of VGEF165 tumor marker based on "signal off" and "signal on" strategies using an anti-VEGF165 aptamer immobilized BSA-gold nanoclusters/ionic liquid/glassy carbon electrode, Biosens Bioelectron, 74 (2015) 369375.

[77] M. Amouzadeh Tabrizi, M. Shamsipur, L. Farzin, A high sensitive electrochemical aptasensor for the determination of VEGF165 in serum of lung cancer patient, Biosens Bioelectron, 74 (2015) 764-769. 
[78] H. Ilkhani, M. Sarparast, A. Noori, S. Zahra Bathaie, M.F. Mousavi, Electrochemical aptamer/antibody based sandwich immunosensor for the detection of EGFR, a cancer biomarker, using gold nanoparticles as a signaling probe, Biosens Bioelectron, 74 (2015) 491-497.

[79] C.S. Ferreira, C.S. Matthews, S. Missailidis, DNA aptamers that bind to MUC1 tumour marker: design and characterization of MUC1-binding single-stranded DNA aptamers, Tumour Biol, 27 (2006) 289-301.

[80] C.S.M. Ferreira, K. Papamichael, G. Guilbault, T. Schwarzacher, J. Gariepy, S. Missailidis, DNA aptamers against the MUC1 tumour marker: design of aptamerantibody sandwich ELISA for the early diagnosis of epithelial tumours, Anal Bioanal Chem, 390 (2008) 1039-1050.

[81] Z. Mi, H. Guo, P.C. Kuo, Identification of osteopontin-dependent signaling pathways in a mouse model of human breast cancer, BMC Research Notes, 2 (2009) 119.

[82] S.G. Meirinho, L.G. Dias, A.M. Peres, L.R. Rodrigues, Development of an electrochemical RNA-aptasensor to detect human osteopontin, Biosens Bioelectron, 71 (2015) 332-341.

[83] F. Kuralay, S. Campuzano, J. Wang, Greatly extended storage stability of electrochemical DNA biosensors using ternary thiolated self-assembled monolayers, Talanta, 99 (2012) 155-160.

[84] S. Campuzano, et al., Ternary monolayers as DNA recognition interfaces for direct and sensitive electrochemical detection in untreated clinical samples, Biosens Bioelectron, 26 (2011) 3577-3583.

[85] R.Y. Lai, K.W. Plaxco, A.J. Heeger, Aptamer-based electrochemical detection of picomolar platelet-derived growth factor directly in blood serum, Anal Chem, 79 (2007) 229-233.

[86] L.R. Schoukroun-Barnes, F.C. Macazo, B. Gutierrez, J. Lottermoser, J. Liu, R.J. White, Reagentless, structure-switching, electrochemical aptamer-based sensors, Annu Rev Anal Chem, 9 (2016) 163-181. 
[87] M.A. Pellitero, A. Shaver, N. Arroyo-Currás, Critical Review-Approaches for the Electrochemical Interrogation of DNA-Based Sensors: A Critical Review, J Electrochem Soc, 167 (2020) 037529.

[88] A. Díaz-Fernández, R. Miranda-Castro, N. Díaz, D. Suárez, N. de-los-SantosAlvarez, M.J. Lobo-Castañón, Aptamers targeting protein-specific glycosylation in tumor biomarkers: general selection, characterization and structural modeling, (2020 submitted).

[89] C.Q. Vu, P. Rotkrua, Y. Tantirungrotechai, B. Soontornworajit, Oligonucleotide hybridization combined with competitive antibody binding for the truncation of a highaffinity aptamer, ACS Combi Sci, 19 (2017) 609-617.

[90] L.S. Green, Inhibitory DNA ligands to platelet-derived growth factor B-chain, Biochemistry-Us, 35 (1996) 14413-14424.

[91] G. Mahlknecht, R. Maron, M. Mancini, B. Schechter, M. Sela, Y. Yarden, Aptamer to ErbB-2/HER2 enhances degradation of the target and inhibits tumorigenic growth, Proc Natl Acad Sci, 110 (2013) 8170-8175.

[92] J.D. Cohen, et al., Detection and localization of surgically resectable cancers with a multi-analyte blood test, Science, 359 (2018) 926-930.

[93] N. Savory, K. Abe, K. Sode, K. Ikebukuro, Selection of DNA aptamer against prostate specific antigen using a genetic algorithm and application to sensing, Biosens Bioelectron, 26 (2010) 1386-1391.

[94] C.L. Chaffer, R.A. Weinberg, A perspective on cancer cell metastasis, Science, 331 (2011) 1559-1564.

[95] Z. Shen, A. Wu, X. Chen, Current detection technologies for circulating tumor cells, Chem Soc Rev, 46 (2017) 2038-2056.

[96] Y. Zhao, D. Xu, W. Tan, Aptamer-functionalized nano/micro-materials for clinical diagnosis: isolation, release and bioanalysis of circulating tumor cells, Integr Biol, 9 (2017) 188-205. 
[97] Y. Song, et al., Selection of DNA aptamers against epithelial cell adhesion molecule for cancer cell imaging and circulating tumor cell capture, Anal Chem, 85 (2013) 4141-4149.

[98] H. Shen, et al., A novel label-free and reusable electrochemical cytosensor for highly sensitive detection and specific collection of CTCs, Biosens Bioelectron, 81 (2016) 495-502.

[99] C. Shen, S. Liu, X. Li, M. Yang, Electrochemical detection of circulating tumor cells based on DNA generated electrochemical current and Rolling Circle Amplification, Anal Chem, 91 (2019) 11614-11619.

[100] J.-X. Liu, N. Bao, X. Luo, S.-N. Ding, Nonenzymatic amperometric aptamer cytosensor for ultrasensitive detection of circulating tumor cells and dynamic evaluation of cell surface N-glycan expression, ACS Omega, 3 (2018) 8595-8604.

[101] L. Tian, et al., Copper (II) oxide nanozyme based electrochemical cytosensor for high sensitive detection of circulating tumor cells in breast cancer, J Electroanal Chem, $812(2018) 1-9$.

[102] D. Ou, D. Sun, Z. Liang, B. Chen, X. Lin, Z. Chen, A novel cytosensor for capture, detection and release of breast cancer cells based on metal organic framework PCN-224 and DNA tetrahedron linked dual-aptamer, Sens Actuat B-Chem, 285 (2019) 398-404.

[103] D. Shangguan, et al., Aptamers evolved from live cells as effective molecular probes for cancer study, Proc Natl Acad Sci, 103 (2006) 11838-11843.

[104] D. Shangguan, Z. Tang, P. Mallikaratchy, Z. Xiao, W. Tan, Optimization and modifications of aptamers selected from live cancer cell lines, Chembiochem, 8 (2007) 603-606.

[105] S.-S. Wang, X.-P. Zhao, F.-F. Liu, M.R. Younis, X.-H. Xia, C. Wang, Direct plasmon-enhanced electrochemistry for enabling ultrasensitive and label-free detection of circulating tumor cells in blood, Anal Chem, 91 (2019) 4413-4420. 
[106] P. Miao, Y. Tang, Gold nanoparticles-based multipedal DNA walker for ratiometric detection of circulating tumor cell, Anal Chem, 91 (2019) 15187-15192.

[107] J. Cao, X.-P. Zhao, M.R. Younis, Z.-Q. Li, X.-H. Xia, C. Wang, Ultrasensitive capture, detection, and release of circulating tumor cells using a nanochannel-ion channel hybrid coupled with electrochemical detection technique, Anal Chem, 89 (2017) 10957-10964.

[108] B. Dou, L. Xu, B. Jiang, R. Yuan, Y. Xiang, Aptamer-functionalized and gold nanoparticle array-decorated magnetic graphene nanosheets enable multiplexed and sensitive electrochemical eetection of rare circulating tumor cells in whole blood, Anal Chem, 91 (2019) 10792-10799.

[109] P. Mallikaratchy, Z. Tang, S. Kwame, L. Meng, D. Shangguan, W. Tan, Aptamer directly evolved from live cells recognizes membrane bound immunoglobin heavy mu chain in Burkitt's lymphoma cells, Mol Cell Proteomics, 6 (2007) 2230-2238.

[110] D. Sun, J. Lu, Z. Luo, L. Zhang, P. Liu, Z. Chen, Competitive electrochemical platform for ultrasensitive cytosensing of liver cancer cells by using nanotetrahedra structure with rolling circle amplification, Biosens Bioelectron, 120 (2018) 8-14.

[111] L. Qu, J. Xu, X. Tan, Z. Liu, L. Xu, R. Peng, Dual-aptamer Modification generates a unique interface for highly sensitive and specific electrochemical detection of tumor cells, ACS Appl Mater Interfaces, 6 (2014) 7309-7315.

[112] F. Li, S. Hu, R. Zhang, Y. Gu, Y. Li, Y. Jia, Porous graphene oxide enhanced aptamer specific circulating-tumor-cell sensing interface on light addressable potentiometric sensor: Clinical application and simulation, ACS Appl Mater Interfaces, 11 (2019) 8704-8709.

[113] D.R. Thévenot, K. Toth, R.A. Durst, G.S. Wilson, Electrochemical biosensors: Recommended definitions and classification, Pure Appl Chem, 71 (1999) 2333-2348.

[114] R. Xu, A. Rai, M. Chen, W. Suwakulsiri, D.W. Greening, R.J. Simpson, Extracellular vesicles in cancer - implications for future improvements in cancer care, Nat Rev Clin Oncol, 15 (2018) 617-638. 
[115] J.-H. Kim, E. Kim, M.Y. Lee, Exosomes as diagnostic biomarkers in cancer, Mol Cell Toxicol, 14 (2018) 113-122.

[116] M.F. Peterson, N. Otoc, J.K. Sethi, A. Gupta, T.J. Antes, Integrated systems for exosome investigation, Methods, 87 (2015) 31-45.

[117] B.S. Chia, Y.P. Low, Q. Wang, P. Li, Z. Gao, Advances in exosome quantification techniques, TRAC Trends Anal Chem, 86 (2017) 93-106.

[118] H. Zhang, Z. Wang, Q. Zhang, F. Wang, Y. Liu, Ti3C2 MXenes nanosheets catalyzed highly efficient electrogenerated chemiluminescence biosensor for the detection of exosomes, Biosens Bioelectron, 124-125 (2019) 184-190.

[119] L. Zhao, R. Sun, P. He, X. Zhang, Ultrasensitive detection of exosomes by targettriggered three-dimensional DNA walking machine and exonuclease III-assisted electrochemical ratiometric biosensing, Anal Chem, 91 (2019) 14773-14779.

[120] X. Yin, T. Hou, B. Huang, L. Yang, F. Li, Aptamer recognition-trigged label-free homogeneous electrochemical strategy for an ultrasensitive cancer-derived exosome assay, Chem Commun, 55 (2019) 13705-13708.

[121] Y. An, T. Jin, Y. Zhu, F. Zhang, P. He, An ultrasensitive electrochemical aptasensor for the determination of tumor exosomes based on click chemistry, Biosens Bioelectron, 142 (2019) 111503.

[122] B. Qiao, et al., An electrochemiluminescent aptasensor for amplified detection of exosomes from breast tumor cells (MCF-7 cells) based on G-quadruplex/hemin DNAzymes, Analyst, 144 (2019) 3668-3675.

[123] Y. Cao, L. Li, B. Han, Y. Wang, Y. Dai, J. Zhao, A catalytic molecule machinedriven biosensing method for amplified electrochemical detection of exosomes, Biosens Bioelectron, 141 (2019) 111397.

[124] H. Xu, C. Liao, P. Zuo, Z. Liu, B.-C. Ye, Magnetic-based microfluidic device for on-chip isolation and detection of tumor-derived exosomes, Anal Chem, 90 (2018) 13451-13458. 
[125] Q. Zhou, A. Rahimian, K. Son, D.-S. Shin, T. Patel, A. Revzin, Development of an aptasensor for electrochemical detection of exosomes, Methods, 97 (2016) 88-93.

[126] https://www.basepairbio.com/, December 23, 2019.

[127] Y.-G. Zhou, et al., Interrogating circulating microsomes and exosomes using metal nanoparticles, Small, 12 (2016) 727-732.

[128] R. Huang, et al., A sensitive aptasensor based on a hemin/G-quadruplex-assisted signal amplification strategy for electrochemical detection of gastric cancer exosomes, Small, 15 (2019) e1900735.

[129] H. Dong, H. Chen, J. Jiang, H. Zhang, C. Cai, Q. Shen, Highly sensitive electrochemical detection of tumor exosomes based on aptamer recognition-induced multi-DNA release and cyclic enzymatic amplification, Anal Chem, 90 (2018) 45074513.

[130] L. Zhang, et al., Evolution of functional six-nucleotide DNA, J Am Chem Soc, 137 (2015) 6734-6737.

[131] S. Wang, et al., Aptasensor with expanded nucleotide using DNA nanotetrahedra for electrochemical detection of cancerous exosomes, ACS Nano, 11 (2017) 3943-3949. [132] F. Wei, J. Yang, D.T. Wong, Detection of exosomal biomarker by electric fieldinduced release and measurement (EFIRM), Biosens Bioelectron, 44 (2013) 115-121. [133] H. Katoh, K. Nakamura, T. Tanaka, S. Satomura, S. Matsuura, Automatic and simultaneous analysis of Lens culinaris agglutinin-reactive $\alpha$-fetoprotein ratio and total $\alpha$-fetoprotein concentration, Anal Chem, 70 (1998) 2110-2114.

[134] A.R. Horvath, et al., From biomarkers to medical tests: The changing landscape of test evaluation, Clin Chim Acta, 427 (2014) 49-57.

[135] M. Duan, et al., Selection and characterization of DNA aptamer for metastatic prostate cancer recognition and tissue imaging, Oncotarget, 7 (2016). 
[136] W. Sheng, T. Chen, W. Tan, Z.H. Fan, Multivalent DNA nanospheres for enhanced capture of cancer cells in microfluidic devices, ACS Nano, 7 (2013) 7067 7076.

[137] W. Zhao, et al., Bioinspired multivalent DNA network for capture and release of cells, Proc Natl Acad Sci, (2012) 201211234.

[138] http://apollodx.com/investors/, December 28, 2019.

[139] J.-F. Chen, et al., Clinical applications of NanoVelcro rare-cell assays for detection and characterization of circulating tumor cells, Theranostics, 6 (2016) 1425 1439 .

[140] https://patentscope.wipo.int/search/en/search.jsf, April 7, 2020.

[141] S. Angione, M. Cooper, J. Coppeta, T. Mulhern, H. Azizgolshani, Regeneratable biosensor and methods of use thereof, EP3548891, 2019

[142] W. Fang, L. Wei, Probe immobilization and signal amplification for polymerbased biosensor, US20100330706, 2015

[143] F. Chunhai, Y. Fan, Z. Xiaolei, H. Qing, Integrated type microfluidic electrochemical biosensor system and method for rapid biochemical analysis, US20150153300, 2015

[144] M.B. Kjelstrup, C. Hejesen, K.V. Gothelf, Z. Zhang, Detection of non-nucleic acid analytes using strand displacement exchange reactions, EP2895617, 2015

[145] M.B. Gu, J.W. Park, T. Rameshwar, Aptamers screening method based on graphene without target immobilization and the aptamers obtained from the method, US20140363808, 2016

[146] C. Ban, Y.-K. Kim, H. Jo, S. Lee, H.J. Youn, DNA aptamer specifically binding to EN2 (ENGRAILED-2) and use thereof, US20160187342, 2016

[147] W.R. Pagels, Systems and methods for diagnostic testing, US20150268186, 2015

[148] S.J. Pearton, T. Lele, Sensors using high electron mobility transistors, US20110074381, 2014 
[149] J. Lotvall, J. S.C., R. Crescitelli, Tissue-derived extracellular vesicles and their use as diagnostics, GB2560897 2018

[150] D. Halbert, V. Domenyuk, D. Spetzler, T. Hornung, F. Schafer, N. Xiao, Aptamers and uses therof, US20190317099, 2019

[151] C. Hui, Aptamer for the capture, diagnosis, enumeration, and eradication of circulating tumor cells US20130035630 2013

[152] G.A. Martin, S. Soper, M. Witek, J.J. Yeh, In vitro capture and analysis of circulating tumor cells, EP2919910, 2015 


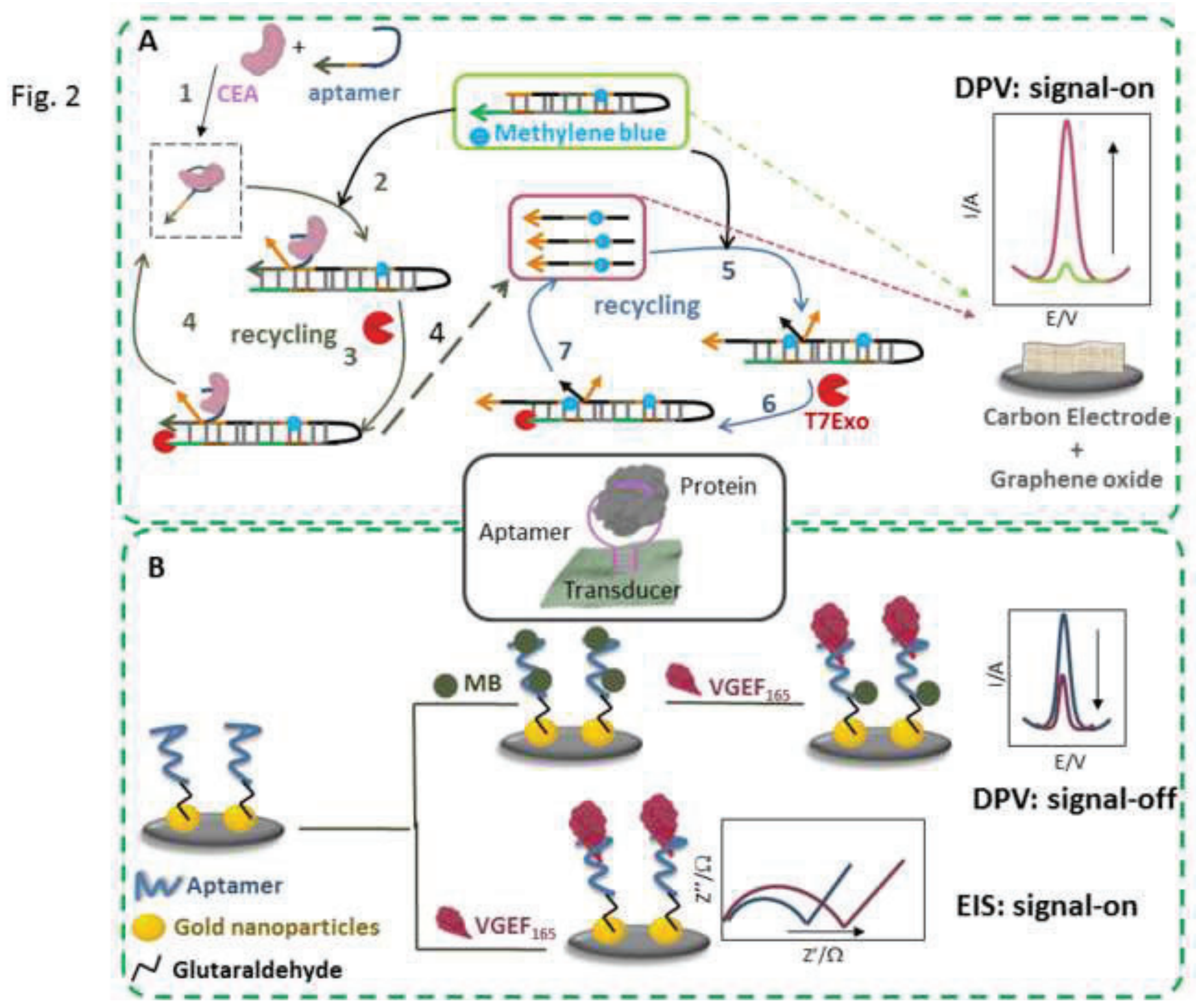




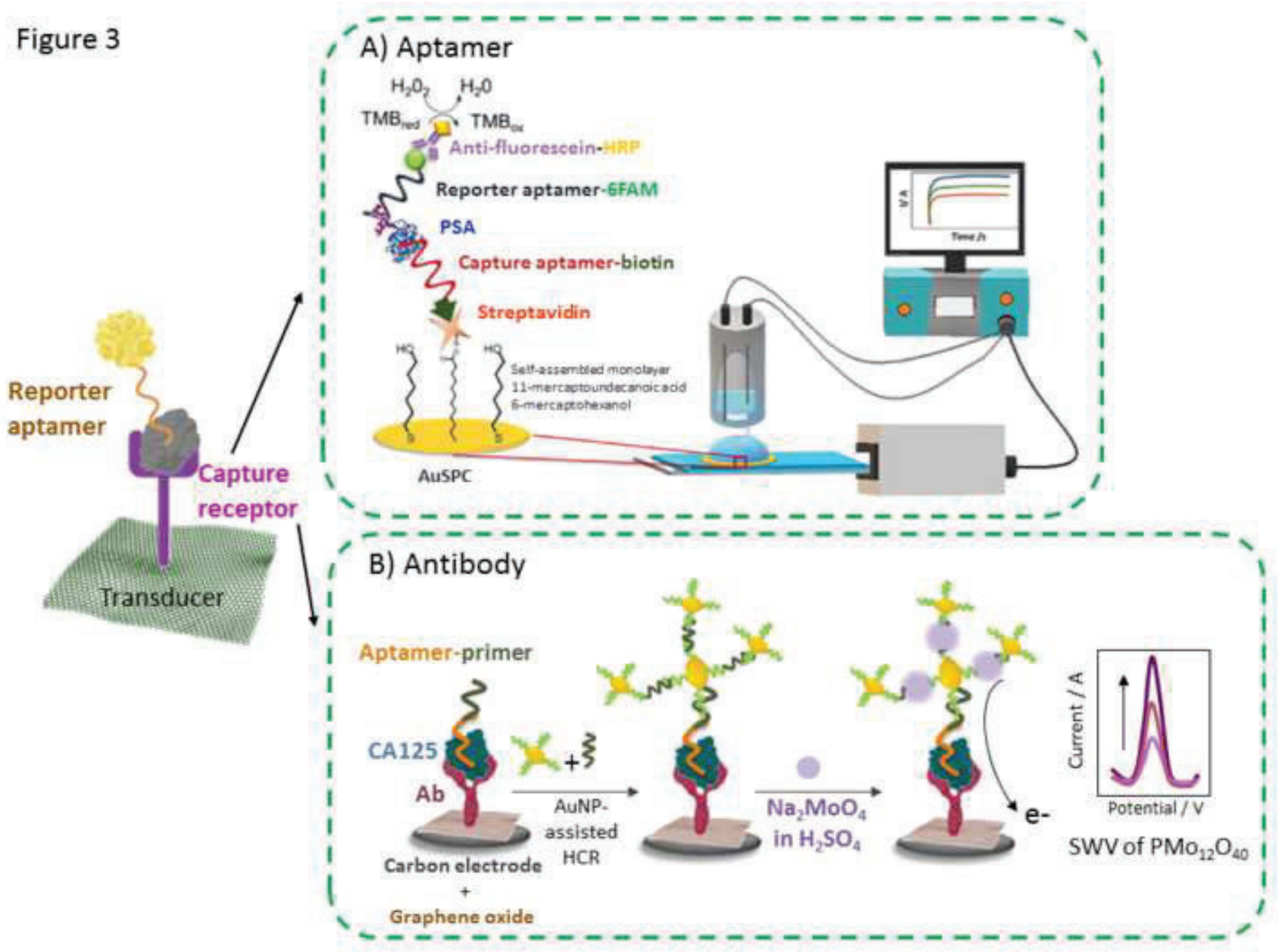


Figure 4

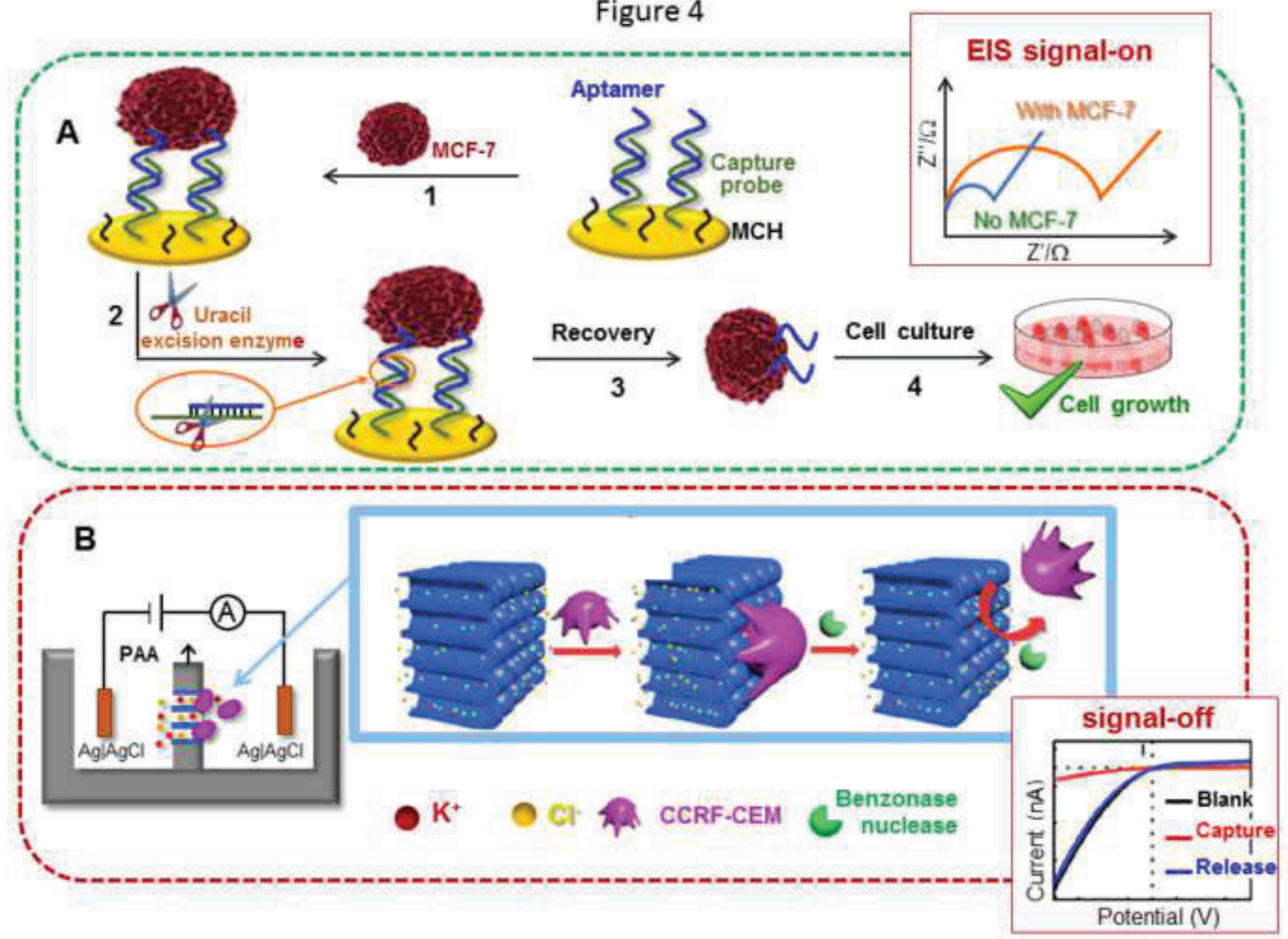



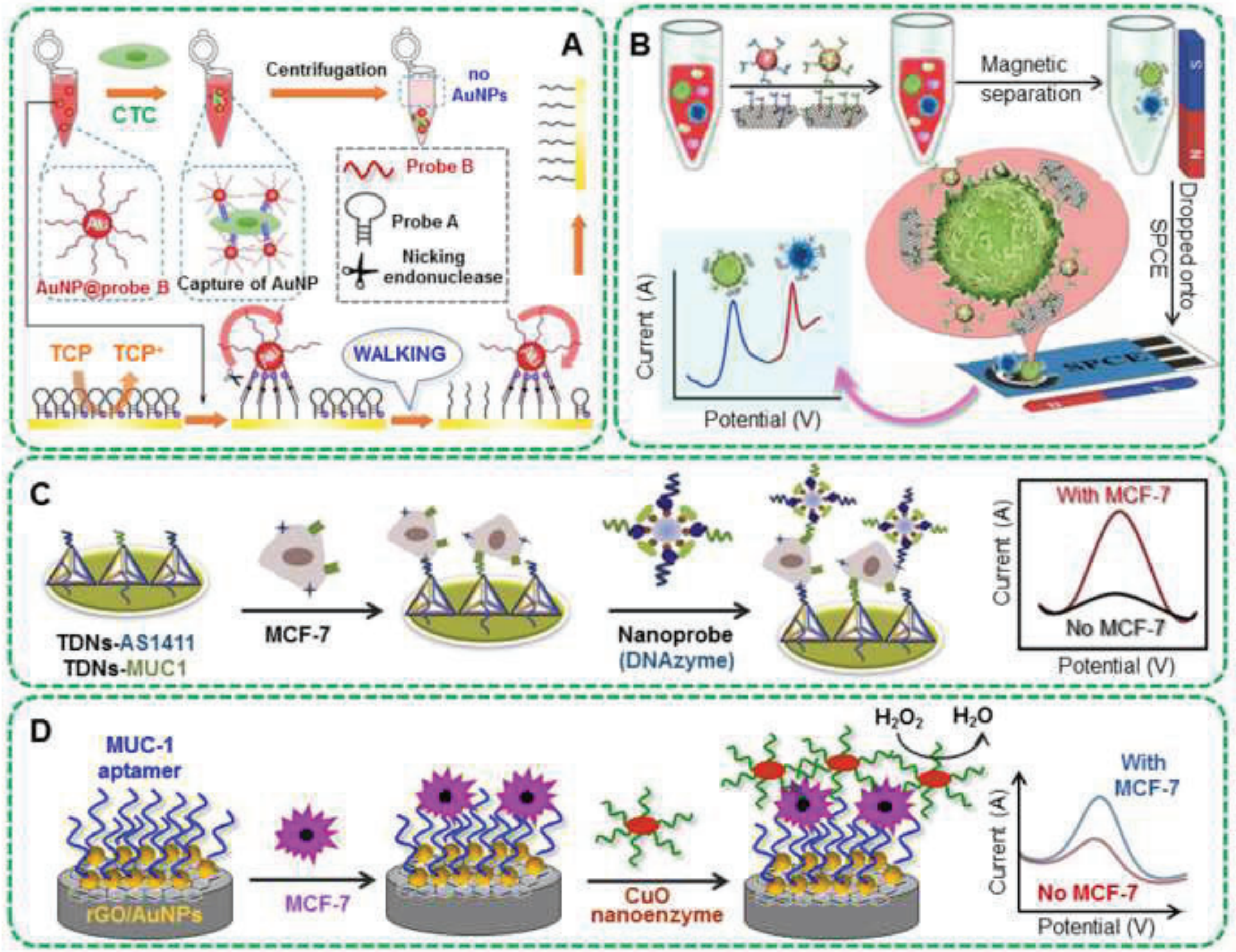


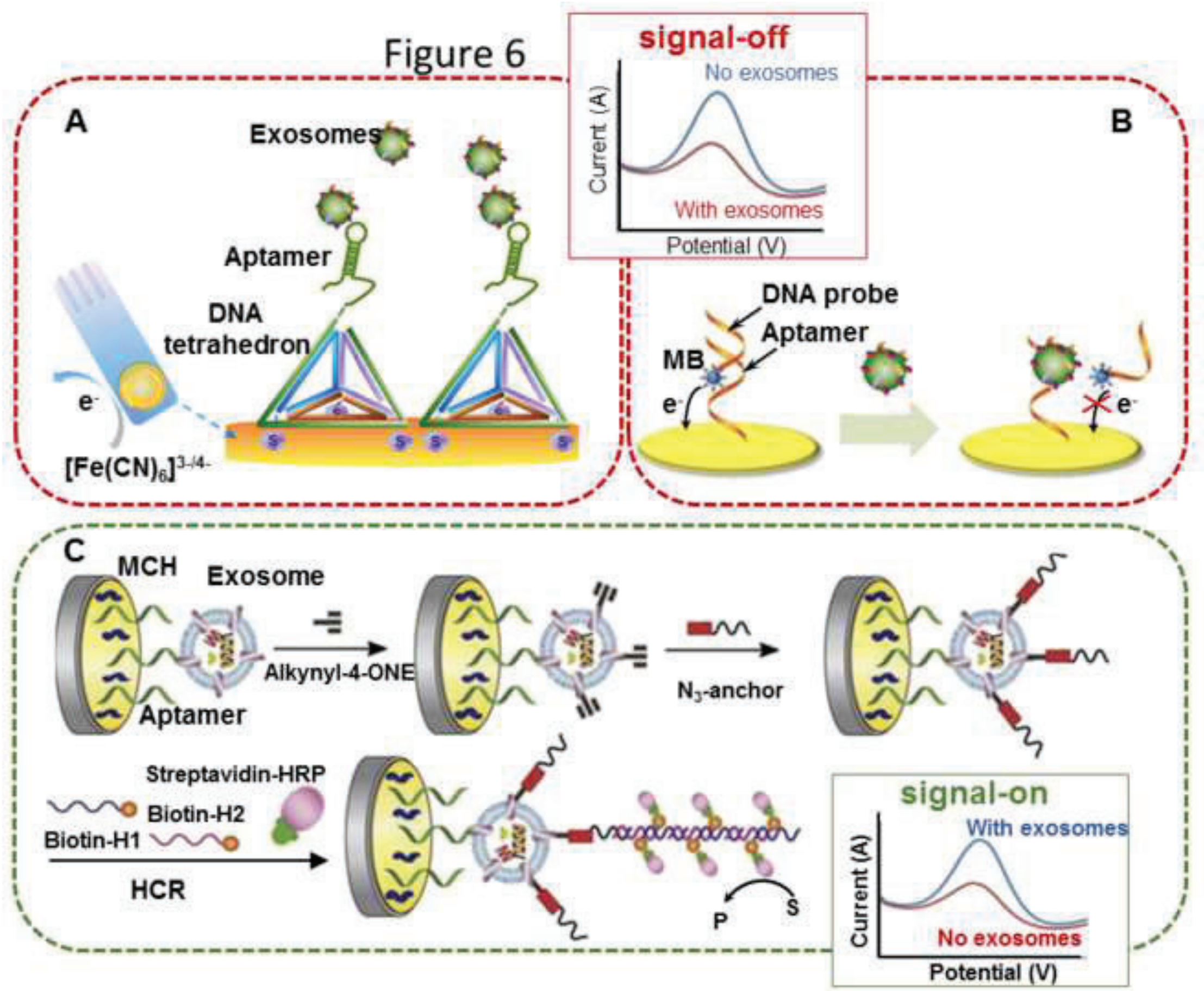




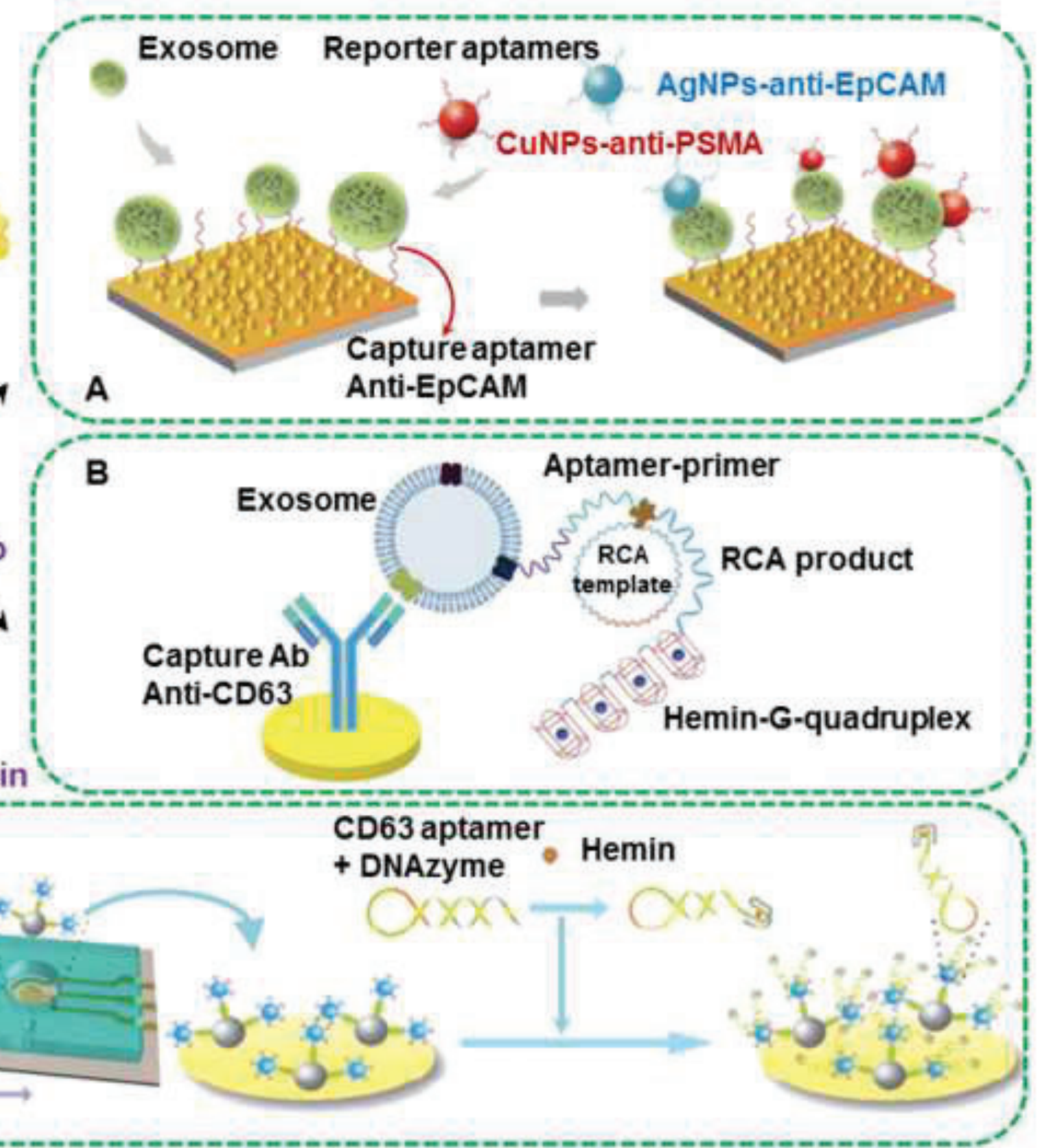

